\title{
Recent Contributions of Elastin-Like Recombinamers to Biomedicine and Nanotechnology
}

\author{
F. Javier Arias ${ }^{*}$, Mercedes Santos, Alicia Fernández-Colino, Guillermo Pinedo and \\ Alessandra Girotti
}

BIOFORGE Research Group, University of Valladolid, CIBER-BBN, Edificio I+D, Paseo de Belen 11, 47011, Valladolid, Spain

\begin{abstract}
The emergence of the new scientific field known as nanomedicine is being catalyzed by multiple improvements in nanoscience techniques and significant progress in materials science, especially as regards the testing of novel and sophisticated biomaterials. This conjuncture has furthered the development of promising instruments in terms of detection, bioanalysis, therapy, diagnostics and imaging. Some of the most innovative new biomaterials are protein-inspired biomimetic materials in which modern biotechnology and genetic-engineering techniques complement the huge amount of information afforded by natural protein evolution to create advanced and tailor-made multifunctional molecules. Amongst these protein-based biomaterials, Elastin-like Recombinamers (ELRs) have demonstrated their enormous potential in the fields of biomedicine and nanoscience in the last few years. This broad applicability derives from their unmatched properties, particularly their recombinant and tailor-made nature, the intrinsic characteristics derived from their elastin-based origin (mainly their mechanical properties and ability to self-assemble as a result of their stimuli-responsive behavior), their proven biocompatibility and biodegradability, as well as their versatility as regards incorporating advanced chemical or recombinant modifications into the original structure that open up an almost unlimited number of multifunctional possibilities in this developing field. This article provides an updated review of the recent challenges overcome by using these recombinant biomaterials in the fields of nano- and biomedicine, ranging from nanoscale applications in surface modifications and self-assembled nanostructures to drug delivery and regenerative medicine.
\end{abstract}

Keywords: Elastin-like recombinamers, self-assembly, stimuli-responsive, tissue engineering, surface modification, drug delivery, nanotechnology.

\section{INTRODUCTION}

Protein based-materials have attracted the attention of numerous researchers in recent years as promising advanced biomaterials for use in the field of biomedicine, especially as a result of recent improvements in recombinant DNA technology, which allow us to design and manufacture materials by exploiting the abilities of natural proteins [1]. Some of the most widely studied protein-derived materials are the socalled elastin like recombinamers (ELRs) [2-4], taking into account its recombinant nature this new nomenclature was proposed [5] in replacement of the more conventional terminology elastin- like polymers (ELPs), which include those first chemically synthesized materials.

Elastin is an elastic, insoluble protein that is present in many tissues such as skin or lung where elasticity is a key requirement. Elastin possesses several extraordinary characteristics, such as an ability to undergo high deformation without breaking and subsequent recovery of the original conformation once the stress disappears. The origin of this ability resides in the structure of the recurrent sequences (VPGVG, VPGG, VGVAPG) found in the soluble elastin

*Address correspondence to this author at the BIOFORGE Research Group, University of Valladolid, CIBER-BBN, Edificio I+D, Paseo de Belen 11, 47011, Valladolid, Spain; Tel: ?????????; Fax: ??????????;

Email: arias@bioforge.uva.es precursor tropoelastin [6]. It is also worth noting that this elastic behavior is an energy-conserving process, thus allowing the resulting elastic fibers to undergo billions of relaxation-stretching cycles [7].

ELRs are smart, genetically engineered biomaterials inspired by natural elastin and based on the very same recurring amino acid sequences as found in tropoelastin. Some of the most relevant characteristics of ELRs, which are derived from those of the natural protein, serve as an example of how elastin's mechanical properties are retained by way of crosslinked ELR matrices [8]. These mechanical properties become more interesting in conjunction with other properties such as biocompatibility, stimuli-responsive behavior and the ability to self-assemble [9-10]. The most widely studied ELRs are based on the recurring pentapeptide sequence ValPro-Gly-Xaa-Gly, where Xaa is any natural amino acid except proline. All functional ELRs present temperature sensitiveness in aqueous solution. Thus, below a characteristic temperature, known as the transition temperature $(\mathrm{Tt})$, the polymer chains remain disordered and relatively extended with a random coil conformation. They are also fully hydrated, mainly by a hydrophobic hydration characterized by the presence of ordered water clathrate-like structures around the apolar moieties in the polymer [11]. Once this Tt is exceeded, this disordered structure is "broken" and the "released" polymer chains adopt an ordered structure known as 
a $\beta$-spiral, which folds hydrophobically to generate a phase separation. The initial step in this process is the formation of triply stranded $\beta$-spiral filaments, which go on to form nanoparticles several hundreds of nanometers in length as a result of continued growth of these filaments. Finally, the filaments come together to form a visibly phase-separated state. The process is completely reversible upon lowering the temperature below the $\mathrm{Tt}$ [10]. However, temperature is not the only stimuli to which ELRs are responsiveness: other external stimuli, such as $\mathrm{pH}$ [12], UV-vis light [13] or ion concentration [14] also have a marked effect on the behavior of ELRs.

Some disagreement still standing about the $\beta$-spiral significance, some authors have demonstrated the existence of other conformations, such as polyproline II in elastin [15], proposing an alternative model where $\beta$-spiral are accompanied by isolated $\beta$-turns [16] and extended structures. [15, 17] The presence of high amount of water in the system, increasing the dynamics of the recombinamer chains would explain the apparent contradictory results obtained by different experimental techniques.

ELRs are obtained by recombinant DNA technologies, which allow an extremely precise control over the amino acid composition. This technology opens up the possibility of designing ELRs with the specific properties required for a certain application $[18,19]$. This design versatility, together with their high biocompatibility, bioactivity and selfassembling behavior, makes ELRs unmatchable materials for studies in the biomedical field [18]. As a result, ELRs have been used in wide variety of applications, such as tissue engineering [20] or drug delivery [21]. Similarly, they have also been applied in the field of nanotechnology due to the range of nanostructures, such as nanofibers [22] or nanoparticles [23], that can be formed from them.

The aim of this review is to try to shed some light on the state-of-the-art of these and other applications of ELRs in the fields of biomedicine and nanotechnology.

\section{ELRs IN TISSUE ENGINEERING}

The potential of ELRs in biomedical engineering has been widely explored over the last decade, particularly in the field of tissue engineering for the construction of bioartificial tissues. Indeed, these recombinant protein polymers can even be suitably designed and molded to restore the structural and biological functions of the extracellular matrix (ECM) [24]. The ability to biosynthesize ELRs guarantees their reproducibility, thereby avoiding the potential variability and risk of using animal-derived structural proteins. Moreover, their characteristics make them biomimetic and re-absorbable materials with a defined mechanical behavior $[25,26]$ that allows them to be cast with a specific topography [27, 28] whilst retaining their tunable temperature responsiveness [29] and controlled structural features. ELR sequences based on the repetition of certain modular ECM structural protein motifs allow the physicochemical [10], mechanical [30], and biological [31] properties of the natural proteins from which they are derived to be reproduced [32]. These properties have made ELRs one of the materials of choice when investigating new biomaterials for biomedical applications.
It has been widely demonstrated that ELRs are able to be formed into plastic or viscoelastic scaffolds for tissue engineering [33]. Due to the possibility of partially substituting their amino acid sequence to modulate potential crosslinking or their ability to self-assemble, ELRs that are able to form physical or chemical gels have been synthesized. Moreover, some of them are injectable and can form a stable continuous implant in situ, a property that is particularly in demand as regards minimizing surgical invasiveness [28, 34, 35]. Such injectable 3D ELR scaffolds have been shown to be suitable for supporting in vitro cell culture and the differentiation of adipose-derived stem cells into chondrocytes without the need to add external supplements [36], and Chaikof's group has confirmed their stealth properties when implanted in vivo, where they show long-term stability in different tissues without inducing an inflammatory response [37]. Although these ELR-based hydrogels confirmed their effectiveness as tissue-engineering scaffolds with excellent mechanical properties and biocompatibility, the absence of a cell-anchorage sequence limits both cell adhesion and subsequent colonization of the artificial scaffold, even if the implant is retained in the host's body for more than a year [37]. In a recent publication from the same group, this deficiency was overcome by both coating their surface with the structural ECM protein fibronectin or integrating this protein into the ELR gel by absorption or cross-linking, which resulted in modulated cell adhesion, viability, proliferation, and migration of both endothelial and mesenchymal stem cells [38].

It is well known that binding between cell-surface receptors and ECM proteins activates the intracellular signaling pathways that deeply influence a cell's behavior and fate [39]. This activation is mostly due to interaction between specific motifs on the ECM proteins and cell receptors. The short amino acid sequences that form protein motifs can easily be incorporated into the sequences of recombinant protein-based polymers (or recombinamer) using standard genetic-engineering techniques, thus endowing these recombinamers with functionality, for example to increase celltransfection efficiency [40], promote angiogenesis [41], inhibit endothelial cell migration [42] or to nucleate bone mineralization [43]. Similarly, the inclusion of integrin-mediated cell-adhesion motifs (short sequences present in several structural ECM proteins) into some advanced scaffolds has been reported to be one of the factors that prevent contraction and scar formation in skin and nerve-tissue regeneration. In this respect, the well-known Arg-Gly-Asp (RGD) guides the colonization of these artificial ECMs by recruiting the host's own cells, thereby avoiding cell-cell binding, limiting wound contraction and aiding tissue regeneration [44]. The inclusion of integrin-binding sites into the ELR backbone also favors material-cell interactions [45].

Several examples of RGD-containing bio-functionalized ELRs have been reported to present higher rates of cell attachment with respect to controls [46, 47]. This enrichment is preserved when the ELR-RGD is coated onto other biologically inert substrates, or is cast in 3D cell supports [48, 49]. Two recent studies in this field described the results obtained by coating scaffolds made of conventional biomaterials as poly(lactic) acid (PLA) or poly(lactide-co-glycolide) (PLGA) with ELR-RGD. In both cases, the ELR layer covering the primary component conferred a stronger cell- 
adhesion ability. In the first work [50], the authors described an alternative and more efficient bio-functionalization of model PLA surfaces achieved using ELR-RGD instead of conventional short peptides containing an RGD motif. PLA scaffolds were either absorbed or covalently grafted with protein material in the form of peptides, ELRs or bovine serum albumin (BSA) and their bio-functionalization efficiency evaluated. All possible combinations were compared in early and late cell-surface interaction studies and three different factors found to influence the process. The first of these is the presence of RGD, which always significant improved early cell adhesion and cell proliferation, and the second is the type of molecule presenting the RGD motif, with ELR-RGD being a significant enhancer with respect to the short peptides-RGD. The final factor is the covalent ligation of molecules to PLA. This resulted in larger cell areas on the ELR-grafted surfaces, cells which acquired a well spread morphology with strong stress fibers, possibly due to better transmission of the mechanical stimuli. The resulting hybrid ELR-PLA scaffolds restricted nonspecific protein adsorption, enhanced cell adhesion and anchorages, and increased the proliferation ratio, thus demonstrating that the use of ELRs is a more efficient strategy for guiding cellular activity than the use of short peptides [50].

In the second example, scaffolds for neural tissue engineering were produced by coating microporous PLGA with various concentrations of ELR-RGD via a simple temperature-dependent sol-gel transition. Subsequent in vitro assays showed that the ELRs improved neural progenitor cell adhesion and proliferation in a concentration-dependent manner. Moreover, when the cell culture on ELR-RGD is grown in combination with retinoic acid, differentiation of the progenitor cells into neuronal and astroglial lineages is induced [51].

The use of ELRs ensures complete composition control and allows the influence of different parameters to be studied as independent components. In this regard, a preliminary study of the influence of cell ligand density and scaffold rigidity on neurite growth has been carried out to improve the performance of a 3D hydrogel formed for neural tissue regeneration. Hydrogel stiffness was modulated by using increasing cross-linker/ELR stoichiometric ratios, whereas the cell adhesion motif density was controlled by homogenously mixing RGD and its scrambled non-adhesive negative control. The resulting data confirmed that the softer and RGDricher 3D hydrogel is the best scaffold for stimulating neurite growth [52].

A similar ELR-RGD scaffold has been used recently to cultivate pancreatic beta-TC6 cells in which the formation of islet-like structures was observed. In this study, the surfaces were easily coated by making use of one of the most characteristic ELR properties, namely the temperature-dependent phase transition that determines the sol-gel transition. In contrast to conventional substrates, the beta cells seeded on the ELR-RGD surfaces showed high cell viability, selforganisation into multicellular spheroids with an islet-like architecture, and clustering, presumably caused by the presence of RGD, which triggers a signaling cascade, in the ELR backbone. Moreover, the pancreatic cells grown on ELRRGD improved insulin expression and secretion stimulated by glucose, increased the expression of cell-to-cell adhesion molecules and of ECM fibrous proteins. The overall results suggested that ELR-RGD promotes pseudoislet formation and therefore that it is a suitable scaffold for manufacturing pancreatic islet cells for transplantation in vitro. [53]

The possibility of employing ELR-RGD materials to improve the regeneration, or induce the differentiation, of endothelium [41], cartilage [36], bone [48, 54], muscle [55], pancreas [53], or neuronal tissue [51] has been described. Interesting results have also been obtained in the case of epithelial oral tissue, for which conventional artificial 3D scaffolds are unable to sustain the potential proliferative capacity of oral epithelial cells during extended culture times. In order to improve cell adhesion on the natural structural protein collagen, an ELR-RGD/collagen mixture was electrospun and cross-linked to fabricate a suitable highly porous epithelial 3D scaffold [56]. The nanofiber 3D ELR scaffold is initially cultivated with human fibroblasts that are able to proliferate, infiltrate the network and neo-synthesize their own ECM, finally forming a lamina propria equivalent. Co-culture with oral epithelial cells seeded over this lamina equivalent generates a non-keratinized, multilayered oral epithelial mucosal equivalent. The 3D hybrid scaffold is able to sustain in vitro culture for six weeks. Moreover, it was found to express the specific oral epithelial marker and is histologically very similar to the native version. In contrast, the collagen-only electrospun 3D scaffold used as negative control was poorly colonized by the cells and its resulting epithelium was thinner [57]. Other types of epithelial cells have also been found to benefit if cultured on ELR-RGD as a substrate for subsequent subretinal transplantation. Indeed, ELR-RGD supports are able to sustain the growth and maintain the phenotype, and functional characteristics of retinal pigment epithelial cells $[58,59]$.

RGD is not the only cell adhesion motif engineered into an ELR back-bone. Thus, Tirrell and coworkers have compared the in vitro cell-adhesion properties of bidimensional ELR scaffolds containing the human fibronectin motifs RGD or Arg-Glu-Asp-Val (REDV) [47, 60, 61]. Although both these motifs were found to enhance the adhesion of HUVEC endothelial cells, the former was more efficient than the latter, which, in contrast, specifically interacts with the endothelium $[62,63]$.

The porosity of the artificial scaffold has been reported to be one of the parameters that induce regeneration for pore diameters ranging from 40 to $140 \mu \mathrm{m}$ [64]. As well as in regenerative medicine, another important property of a temporary scaffold is that it must degrade and be absorbed once the host can neo-synthesize its own ECM. In light of this, a number of trigger-biodegradable biomaterials have been biosynthesized $[65,66]$. Both these features can be achieved in 3D scaffolds obtained by chemical cross-linking of an enzymatically biodegradable ELR-REDV. Thus, HUVECs cultured in highly interconnected porous 3D hydrogels are able to infiltrate the porous network and acquire a well spread morphology [67]. The same ELR-REDV and collagen have also been enzymatically cross-linked using variable ratios of both proteins to form 3D scaffolds. The resulting collagenELR scaffolds improved the elasticity and bioactivity in terms of adhesion selectivity and proteolytic sensitivity with 
respect to those formed from collagen alone. A comparison of HUVEC and fibroblast cultures grown on the hybrid scaffolds confirmed that REDV specificity (in terms of both morphology and proliferation rate) was ratio-dependent. This study therefore suggests that the collagen-ELR ratio can be varied to fit the characteristics of different tissues, thereby preventing hypertrophy of the scar and modulating angiogenesis [63].

A further bioactive sequence identified in a secreted heparin-binding protein (CCN1) that is expressed at injuryrepair sites was recently incorporated into a triblock copolymer to enhance cell adhesion. This 20-mer peptide, namely $\mathrm{V} 2$, specifically binds to integrin $\alpha_{\mathrm{v}} \beta_{3}$, membrane receptors present in HUVECs. As a result, the HUVECs cultured on the ELR-V2 adhered, spread, migrated and also showed a quiescent phenotype in the presence of an integrin-mediated stimulus [68].

A series of tailored-made ELRs have been synthesized in order to obtain adult cardiomyocytes. In this case, due to their poor proliferation, instead of inserting a cell-adhesion motif into the ELR sequence, the authors preferred to include the receptor-binding domain of insulin-like growth factor binding protein 4 (IGFBP4), which promotes the differentiation of embryonic stem cells into cardiomyocytes. The ELRIGFBP4 sol-gel transition allowed stable coating of the culture substrate and the possibility of cell differentiation was subsequently evaluated. A high IGFBP4 concentration is required to induce this differentiation in a standard culture as it is very unstable. A comparison of the results obtained in this study showed that absorbed ELR-IGFBP4 is more efficient than absorbed IGFBP4 alone or the standard method of cardiomyocyte differentiation involving continuous addition of soluble IGFBP4 to the medium. As such, the functionalized ELR-IGFBP4 improves IGFBP4 stability, thereby resulting in a stronger and constant effect on the culture [69].

The studies highlighted above indicate that the use of ELRs to construct 2/3D scaffolds or to improve the bioactivity of conventional materials has significantly increased the performance of conventional scaffolds. Moreover, their modular nature means that the function of biomaterials can be enhanced by redesigning their amino acid composition and adding bioactive motifs that may convert the scaffold from being a mere support to a vector that performs the fine and delicate role of cell-material communicator during reconstitution of the new host tissue.

\section{APPLICATION OF ELRS IN SURFACE ENGINEER- ING}

Surface engineering is an area in the field of biomaterial science devoted to the control and modification of surfaces and interfaces in order to study the molecular mechanisms underlying protein adsorption and cell-extracellular interactions. A large number of biological reactions occur either on surfaces or at interfaces, and cell behavior can be conditioned by a given well-defined topography and bioactivity of these surfaces. Moreover, in the field of implantable devices, surface contacts with the organism dictate cellular behavior and biointegration. In light of the above, the development of appropriate systems that mimic in vivo cellular environments in order to enable in vitro studies of cell-matrix interactions is a key requirement for future progress in several areas of bioscience and biotechnology. [70]

The ability to manufacture surface coatings that are biocompatible and stable under physiological conditions is a valuable objective in surface engineering in order to design devices with an improved biological performance. In this sense, ELRs are excellent candidates for the development of smart surfaces as, together with their extensive potential to self-assemble, their sequence, functionality and bioactivity can be closely controlled using recombinant technologies.

\section{Modification of Surface Topography by ELRs}

The design of systems with a well-defined topography and controlled chemical and mechanical properties is a hot research topic due to their potential biomedical applications, especially for improving cell-material interactions [71, 72]. Modification with stimuli-responsive ELRs allows surfaces to vary their physical and chemical properties in response to external stimuli, which is often essential for endowing advanced materials and devices with desirable features.

In this sense, Bandiera [73] has described the behavior of different cell lines cultured on surfaces coated with an ELR that adopts a defined pattern of concentric circles. The good adhesiveness displayed by all the cell lines studied is noteworthy, with the specific behavior depending on the cell type concerned. The difference in cell response appears to reside in the ability of cells to somehow discriminate the physical structure of the substrate. Thus, human endothelial and epithelial cell lines align along the grooves, probably in the direction in which they encounter the least resistance, as already described for other biological systems. [74]

To study the influence of different topographies on cell behavior, Garcia-Arevalo et al. carried out a comparative analysis of the precise contribution and importance of two different surface topographies, namely nanofibers and films, on cell behavior [45]. Inert surfaces were covered with a film or an electrospun layer of an aqueous solution of ELRs bearing a specific adhesion sequence such as RGD. Surfaces with different topographies showed different properties in terms of wettability, roughness and surface free-energy. The morphological and proliferative responses of the seeded human fibroblasts were analyzed, and the authors concluded that higher proliferation rates were obtained for those surfaces coated with films which presented a higher surface energy and were more hydrophilic. The lower proliferative values for surfaces covered with fibers was due to the greater adsorption of non-specific proteins from the culture medium, thereby hindering cell-surface interactions. The surface adhesion and proliferative values for both these topographies were higher for those surfaces coated with the RGDcontaining ELR than for the control surfaces covered with an ELR lacking the RGD domain [45].

Similarly, Martin et al. have fabricated 3D structures made of ELR-based hydrogels by means of replica molding. These structures have a fully controlled surface microtopography in addition to tunable mechanical properties and a smart nature. These surfaces exhibited grooves or pillars with different dimensions and distances. The controlled topography and bioactivity resulting from the RGD domain are noteworthy factors to study and, eventually, to regulate cell 
behavior [27]. The hydrogels were obtained by chemical cross-linking on top of PDMS stamps; their swelling and mechanical properties could be modulated by varying the polymer:cross-linker ratio. The thermoresponsive behavior of the starting ELRs was maintained in the hydrogel, which exhibited different dimensions above and below its transition temperature, without topography modification [27]. Micropatterned gels were subsequently obtained from elastinlike amphiphilic multiblock copolymers with reversible thermogelling properties under mild, physiological conditions. In this case, the one-step physical gelation process comprises heating the ELR solution above its gelation temperature on top of a PDMS mould (see Fig. 1). The mechanical properties of the hydrogel can be tuned by varying the polymer solution concentration [28]. Micropatterned membranes have been obtained from ELRs containing an RGD domain that incorporate both biomolecular and physical signaling by Tejeda-Montes et al. [75] These membranes are obtained by using hexamethylene diisocyanate (HDMI) as chemical cross-linker. Rat mesenchymal stem cells (rMSCs) attach to membranes both with and without RGD but only exhibit well-developed focal adhesion mediated by integrin binding for those containing an RGD domain. In membranes with surface topographies, cells show morphological variations and contact guidance depending on the surface topography, exhibiting an aligned and thin morphology on channels and growing within and around the posts, with actin cytoskeletons engulfing them. This response of the cells to the membrane's biomolecular and physical features suggests that both elements could be tailored to synergistically alter specific cell behavior. These microstructured substrates simulate the microscale structure of tissues and could be used as implantable platforms or as a substrate for studying spatially controlled cell behavior.

In order to study the influence of surface chemistry and topography on bone marrow mesenchymal stem cell proliferation and differentiation, micropatterned PIPAAm films were prepared and modified by adsorption of an elastin-like polymer containing an adhesion domain (ELR-RGD). Taking advantage of the thermal responsiveness of the ELRRGD, rhythmic temperature changes were applied to flex and contract the 2D scaffold in an attempt to mimic mechanical stress on the cells and to provide dynamic culture conditions that are expected to improve bone formation. The presence of the recombinamer proved crucial for maintaining cell attachment under dynamic culture conditions, as corroborated using control tissue culture polystyrene surfaces (TCPS), for which the number of attached cells decreased with time under the same conditions [48].

\section{Biofunctionality Control Using ELRs}

Many physicochemical methodologies have been proposed to modify the chemical and topographical features of substrates. Initial research mainly focused on the adsorption of natural proteins and short peptides. However, the use of engineered proteins can provide the advantages of both strategies and avoid the main drawbacks concerning the immunogenic problems presented by some proteins or the loss of effectiveness of oversimplified peptides. [20] In this
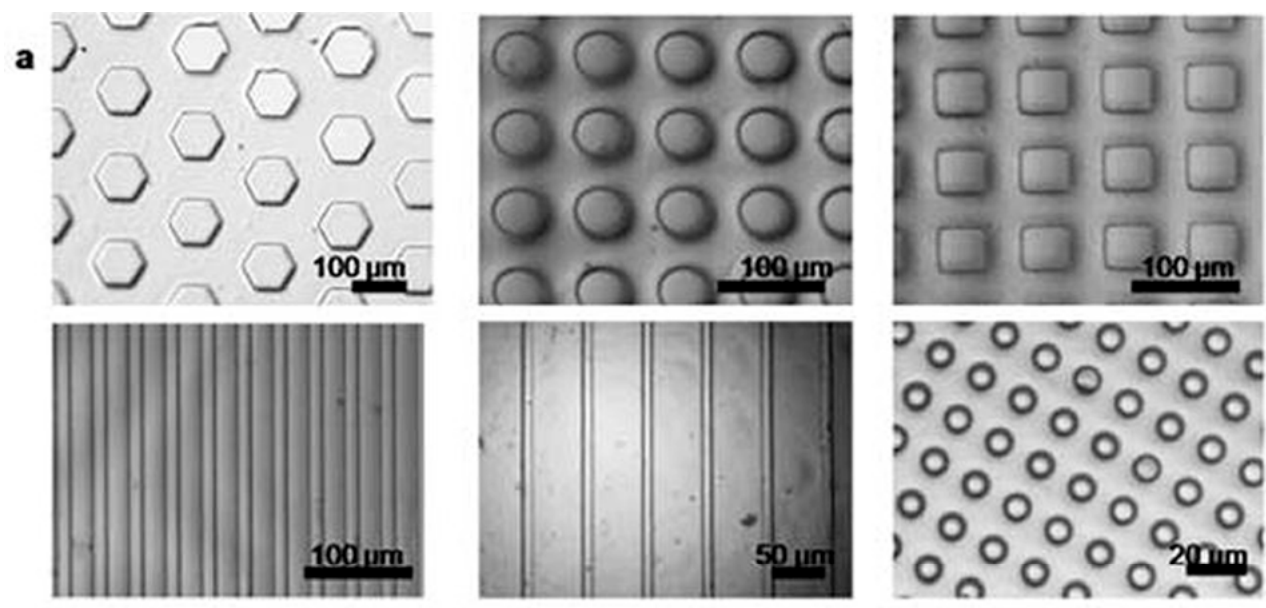

b
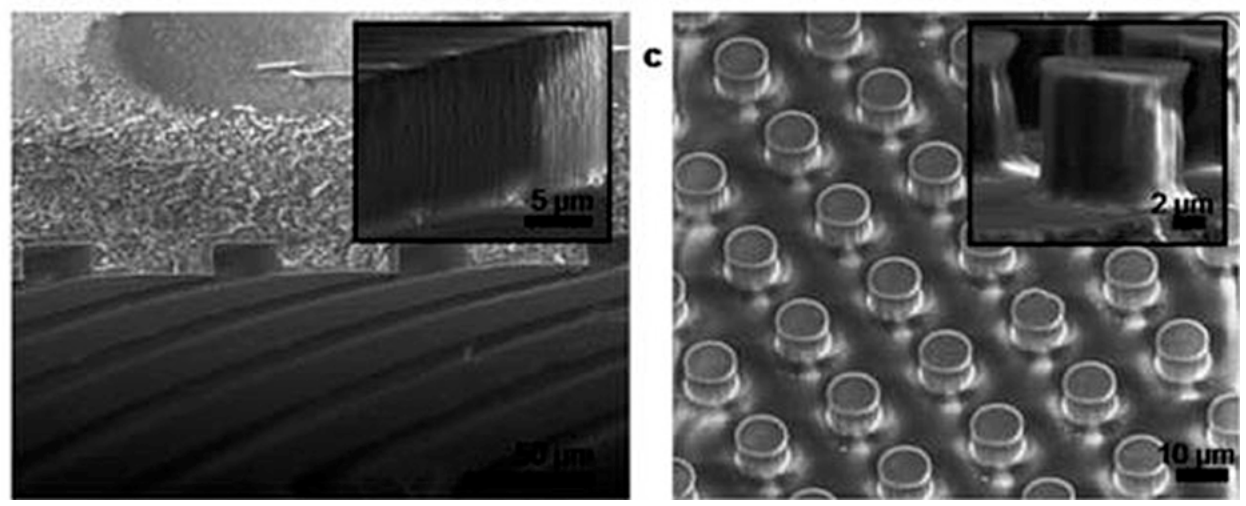

Fig. (1). Micropatterned gels with different features obtained by ELR replica molding. Adapted with permission from Soft Matter [28]. 
sense, Srokowski and Woodhouse have studied the physical adsorption of a family of ELRs that differ in terms of molecular weight and sequence length onto a Mylar surface as a way of understanding how surface properties can influence their bioactivity, especially their hemocompatibility. This study showed that the amount of adsorbed ELR increased with ELR sequence length and that surface coverage and stability improved, whereas hydrophilic adhesion forces and/or wettability decreased, with ELR sequence length. In other words, the longest polypeptides formed films with greater structural flexibility and associated water content. The dynamic nature of the adsorbed layer may be an important factor that contributes to its biological response [76]. Additionally, a decrease in fibrinogen accretion and platelet adhesion was observed for ELR-coated compared to uncoated surfaces, with the longest ELR coatings exhibiting lower levels of fibrinogen adsorption and platelet adhesion and therefore being the best thromboresistant coatings [77].

Janorkar et al. have studied the surface modification of TCPS plates by adsorption of differently modified ELRs and have demonstrated the influence of the physicochemical nature of the substrate on cell activity. Thus, ELRs chemically conjugated with polyacrylic acid (ELR-PAA) and with polyethyleneimine (ELR-PEI) were adsorbed onto TCPS plates, thereby leading to oppositely charged surfaces. Primary hepatocytes were cultured on these surfaces and opposite effects on cell morphology and differentiated functions were found for them. For example, hepatocytes were found to spread on ELR-PAA coated surfaces but low liver-specific function was detected, whereas hepatocytes formed spheroids on positively charged ELR-PEI surfaces and exhibited enhanced function for up to 21 days, as deduced from levels of urea and albumin production, with both ELR and PEI being required for this morphological control and functional enhancement [78].

Surfaces based on natural polymers such as chitosan have also been modified to increase their bioactive character. In this sense, Barbosa et al. adsorbed different bioactive ELRs onto a chitosan hydrogel surface by simple deposition of the ELR dissolved in a water-based solution. Those chitosan hydrogels coated with ELRs containing an osteoconductive sequence promoted the deposition of hydroxyapatite (HAP) onto the surface [79]. Smart thin coatings obtained using ELRs containing the RGD cell-attachment sequence enhanced osteoblast adhesion and proliferation in comparison with the original chitosan substrate. An intermediate behavior was found in the chitosan coated with an ELR lacking the RGD sequence. [80] These films have great potential as biomimetic biomaterial coatings.

An ELR bearing the RGD adhesion motif has also been used recently to biofunctionalize an implantable material, namely a PLA model surface, in order to induce the regeneration of damaged tissue. In this application, hydrophobicity and lack of bioactive properties appear to be drawbacks for rapid and effective biointegration. To overcome this handicap, PLA-based biomaterials were chemically functionalized in order to be able to graft engineered proteins onto them. The results suggest that ELR functionalization creates a non-fouling coating that is able to restrict nonspecific protein adsorption [50]. Thus, covalently functionalized ELR surfaces are able to elicit twice as much cell at- tachment (from $25 \%$ to $50 \%$ of cell spreading area) with respect to samples with adsorbed ELRs. Strong attachment to the surface improves both cell spreading, which is related to transmission of the mechanical properties from the surface to the cell via covalent grafting, and molecular stability in terms of prolonged efficacy and reproducibility.

Other efforts have been devoted to modifying materials other than polymers, such as metals, in order to improve their properties for use as implantable materials by taking advantage of the features of ELRs. Some metals are widely used to manufacture implants due to their mechanical and physical features, such as their corrosion resistance, which is a central aspect of their biocompatibility. Recently, titanium has been coated with ELRs in order to improve its bioactivity and biocompatibility. Thus, Gonzalez et al. have functionalized $\beta$-type Ti alloys with ELRs by chemical surface modification in order to make implants for use in bone tissue engineering. The covalent immobilization of a recombinamer bearing the bioactive RGD motif onto Ti surfaces adequately functionalized by activation with oxygen plasma treatment induced higher cell recruitment and spreading of the osteoblast cells than for control surfaces. Consequently, these results demonstrate the great potential of ELR-coated Ti alloys for use as implantable materials, especially when taking into account that they also exhibit mechanical features similar to those of human cortical bone [81].

\section{The Layer-by-Layer Approach to Surface Coating}

A further physicochemical methodology proposed recently for modifying the properties of different surfaces is known as the layer-by-layer approach (LbL). The sequential LbL adsorption of polyelectrolytes is a simple and versatile technique for the assembly of multilayer coatings [82]. The principle behind $\mathrm{LbL}$ adsorption lies in the existence of multiple intermolecular interactions, such as electrostatic contacts, hydrophobic interactions and hydrogen bonding, in which the cooperative effects of multipoint attractions play the most important role. Ultrathin coatings based upon ELR conjugates offer tremendous potential for enhancing the biocompatibility of substrata, thereby generating bioactive and biomimetic surfaces that are able to modulate cell-substrate interactions [83].

As an example, Golonka et al. have used the LbL methodology to electrostatically self-assemble charged polymers consisting of ionic elastin-like recombinamers (ELRs), thus leading to thermoresponsive multilayer thin films on quartz or silicon. The ELR-containing lysine units served as a polycation and the ELR with glutamic acid served as a polyanion, both of which carry evenly distributed and equidistant charged moieties at $\mathrm{pH} 7$. The multilayer film was found to be temperature-responsive under physiological conditions and to be resistant to salt solutions, with this robustness being an important factor for subsequent application as a biocompatible nanocoating [84]. ELRs chemically modified to carry different charges have been used by Swierczewska et al. for LbL electrostatic self-assembly. The charged polymers consisted of elastin-like recombinamers coupled to polyethyleneimine (ELR-PEI), and therefore positively charged, and to polyacrylic acid (ELR-PAA) opposite; negatively charged. When deposited on glass substrates, these ultrathin ELR-based multilayer nanoscale coatings promote 
cell adhesion and proliferation in comparison with uncoated surfaces despite the polymer structure lacking a celladhesion domain. Cell proliferation and cytoskeletal organization can be enhanced by increasing the number of bilayers, thus indicating that both the thickness and mechanical integrity of the ELR multilayer play an important role in modulating the cellular response [85].

The LbL build-up of self-assembled multilayer films based on electrostatic and hydrophobic interactions, with alternating layers of chitosan and an ELR containing an osteoconductive sequence (HAP), was reported by Barbosa et al. [83] Modified surfaces with this ELR-HAP as the outermost layer maintained the temperature-responsive behavior of the starting ELR, thus combining the facile and versatile fabrication of multilayers with the concept of smart surfaces. In the same way, another smart thin biomimetic coating has been successfully fabricated using the same chitosan and another ELR containing an RGD adhesion sequence. This robust nanostructured multilayer coating was designed to have smart properties, with an acute and independent response towards temperature, $\mathrm{pH}$ and ionic strength. In vitro studies showed enhanced SaOs-2 osteoblast-like cell adhesion and activity for ELR-RGD coatings in comparison with those substrates for which the outermost layer was chitosan or scrambled RDG biopolymer coatings [83].

The LbL technique can also be used to coat surfaces with complex geometries and shapes and can be extrapolated to three-dimensional structures. Thus, recent studies in this field have been devoted to the construction of microcapsules by the sequential adsorption of chitosan and a biomimetic elastin-like recombinamer containing an RGD sequence into nanostructured layers on inorganic microcapsule templates. Biocompatible microcapsules are especially interesting due to their potential role as carriers of biomolecules. These microcapsules were made starting from $\mathrm{CaCO}_{3}$ particles in the presence of BSA, which were coated with a different number of ELR-chitosan bilayers. After construction, the core was chelated with EDTA to form hollow microcapsules. These microcapsules were able to modify their size and permeability due to the thermoresponsive nature of ELRs and, in addition, were found to be non-cytotoxic towards mouse fibroblast cells. The presence of different bioactive motifs in the ELRs conferred biological activity on them, thus making them a promising alternative for drug delivery and tissue engineering [86].

We can conclude that the LbL methodology produces robust coatings in substrates with different geometries. These examples also demonstrate that complex molecules like ELRs can be exploited as polyelectrolytes, and the resulting substrates could be useful for biomedical applications due to their thermoresponsive properties, biocompatibility and stability under physiological conditions.

\section{Smart Surfaces by ELR Grafting}

Stimuli-responsive polymers often retain their "smart" behavior, which can be harnessed for sensing applications, when grafted onto surfaces. Covalent attachment is often preferred to weaker interactions for this purpose due to inherent resistance to environmental degradation [87]. ELRs tethered to a surface via covalent bonding in the form of polymer brushes can also be used as stimuli-responsive surfaces because they are able to vary their physical and chemical properties in response to external stimuli. Generally speaking, stimuli-responsive surfaces are able to change their hydrophobicity due to conformational changes that occur around the transition temperature of the attached polymer. Thus, at temperatures below the transition temperature the surface is more hydrophilic because the polymer is in an expanded soluble conformation surrounded by hydrophobic hydration, whereas at temperatures above the transition temperature the polymer is in a collapsed insoluble conformation that results in a more hydrophobic surface. The most common biomacromolecules that can be manipulated by stimuli include $\mathrm{N}$-alkyl substituted polyacrylamide (i.e. PIPAAm), polyalcohols and natural or genetically engineered polypeptides, such as ELRs. Such changes in surface hydrophobicity in response to changes in temperature have been exploited in the field of chromatography by using matrices with grafted PIPAAm to separate substances that interact differently with the matrix, with biomolecules such as proteins adsorbing more strongly onto hydrophobic surfaces [88-90]. Similarly, chemical valves with controlled porosity can be made by grafting smart polymers to porous systems as the polymer transition affects the total free volume of the pores available for the solvent [91].

Controllable bacterial attachment and detachment has been achieved by using smart thermoresponsive surfaces together with ELR biofunctionalized bacteria. The surfaces were microcontact printed with a cell-repellent polymer and the uncoated specific areas biofunctionalized with an ELR covalently grafted to the surface. Five different types of ELR-bacteria conjugates were used for binding to ELRfunctionalized glass via hydrophobic interactions between the ELR molecules. Reversible bacterial attachment and detachment was achieved by controlling the thermoresponsive phase transition of the ELRs. This arrangement solves the problem of bacterial cell death and contamination from cell division that occurs in microfluidic applications [92].

The hydrophobic surface changes make them very attractive for biological applications because most proteins and cells preferentially adsorb to hydrophobic surfaces, thus meaning that cell adsorption and desorption can be triggered [90]. This cell attachment and detachment is controlled by external stimuli such as temperature, $\mathrm{pH}$ and/or ionic strength and makes these surfaces attractive for use in microdevices for cell-based therapies. Cell-harvesting systems and technologies are powerful elements for the development of cell production, especially as regards their subsequent use in human therapies. Indeed, tissue engineering and regenerative medicine will not easily become universally applicable without a reliable source of cells for therapeutic purposes [93].

In this sense, Okano et al. have developed a new technology for cell sheet detachment in an attempt to avoid the physical or proteolytic treatments that result in degradation of cell-surface proteins, which are vital for the cell-to-cell and cell-to-ECM interactions necessary for maintaining tissue structure. Thus, in this approach, cells are cultured on temperature-responsive dishes created by grafting PNIPAAm onto ordinary tissue culture dishes (TCPS). The dish surface is relatively hydrophobic, and therefore suitable for 
cell culture, under physiological conditions. A small temperature reduction causes the surface to become very hydrophilic, thereby releasing confluent sheets of culture cells. These cell sheets, with their deposited ECM, can then be transplanted into the host tissues. This system requires an adequate control of the thickness of the grafted PIPAAm, which is a critical issue for obtaining temperature-switchable attachment/detachment of the cultured cells. [94, 95] Following a similar methodology, Kobatake et al. have developed a system for cell sheet engineering using ELR-coated smart surfaces. Thus, recombinamers carrying an RGD adhesion domain are adsorbed onto a hydrophobic dish. Once confluent, the cells seeded onto the coated plate can be detached from the dish as a sheet by lowering the temperature to 20 ${ }^{\circ} \mathrm{C}$. This change in temperature reverses the co-aggregation and modifies the hydrophobicity of the plate surface, thus allowing cell sheets to be harvested. However, this system only allows cell-sheet detachment together with the previously adsorbed ELRs rather than cell harvesting, thus making it non-reusable. [96]

In contrast to the above procedure, Pierna et al. have recently developed a new, reusable and efficient system for cell and cell-sheet harvesting based on smart surfaces with ELRs with a known molecular design grafted to them via their lysine-rich end as polymer brushes. Thermoresponsive surfaces have been obtained by covalent coupling of tailored ELRs via a "click" chemistry methodology.

The biofunctionalized surfaces switch between cell adherent and non-adherent states with a change in temperature due to the thermoresponsive properties of ELRs. As the ELR carries RGD domains in its structure, these adhesion domains can be exposed or hidden by varying the temperature and can thus be used for cell harvesting. Cell analysis with human fibroblasts shows a high-grade of adhesion to the adherent state of the surface $\left(37^{\circ} \mathrm{C}\right)$ in which the ELR-RGD is in an aggregated form and presents the more polar adhesion domain to the water interface, thus allowing "active" cell adhesion, viability and proliferation. A slight decrease in temperature triggers a reorganization of the recombinamer, thus resulting in exposure of the non-adherent domains and hiding of the RGD adhesion domains and detachment of the cell. This process allows single cells or cell sheets from lines such as fibroblasts and stem cells to be harvested in a quick and clean manner (Fig. 2). This new methodology avoids the drawbacks of previous cell-harvesting technologies as regards close control of the thickness for grafted polymers (PIPAAm) [94] or the inability to reuse them. In this new system [96], an ELR monolayer is end-grafted to the surface in a covalent manner, thus allowing absolute control of the layer thickness. Moreover, the system can be reused over several cell-harvesting cycles due to the thermoresponsive behavior of brush-like grafted ELRs. In short, multiblock ELR design opens the way to the development of much more sophisticated systems that cannot be achieved using other alternatives. [97]

To summarise, as discussed in the previous chapter, surfaces covered with different ELRs can promote cell adhesion, spreading and proliferation, especially when the recombinamers carry a cell-adhesion domain. Additionally, films, multilayers or chemical grafts of these different coatings allow surfaces with different topographies, and there- fore different chemical and physical properties that can be tuned to modulate cell-substrate interactions, to be obtained. These findings represent a clear improvement as regards surface engineering with respect to the systems used previously.

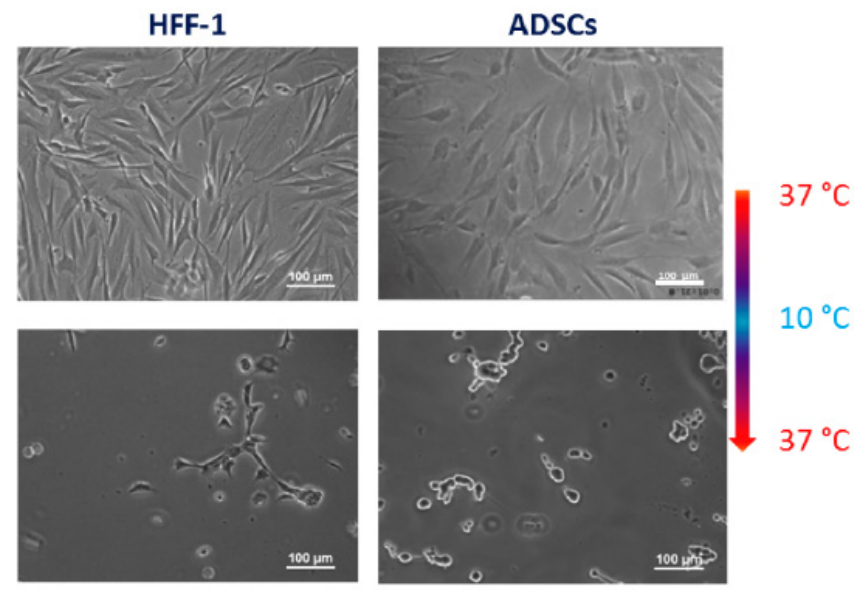

Fig. (2). Cell adhesion and detachment in a cell-harvesting system for fibroblast and ADSC cell lines. Phase-contrast images of the same surface location after incubation at $37^{\circ} \mathrm{C}$ and subsequent low-temperature treatment. Adapted with permission from Biomacromolecules [97].

\section{ELRS FOR DRUG DELIVERY}

The main objective of drug delivery is to get the required amount of active substance to the right place at the appropriate time. Controlled-release systems are commonly used to prolong the time that the therapeutic dose is present effectively in the body using a single dose, and to eliminate or minimize concentrations above that required therapeutically. In such systems, the bioactive agent is incorporated into a support that is generally formed by one or more kinds of materials, usually of a polymeric nature [98]. This section focuses on ELR-based polymeric materials and their role in controlled drug release.

\section{Drug Delivery from ELR-Based Hydrogels}

Hydrogels are three dimensional networks of polymers, peptides or polypeptides with characteristically high water content. This high degree of hydration, together with their porous morphology, is essential for the diffusion of hydrophilic drugs, which is key for their use as vehicles for drug delivery [99]. Relative to hydrophobic drugs, amphiphilic polymeric materials provide both hydrophilic and hydrophobic environments and therefore usually result in enhanced drug solubility [100].

The first elastin-based polymers designed for drug release were simple devices in which a hydrogel of a chemically synthesized poly(VPGVG) was loaded with a watersoluble drug, which was subsequently released by diffusion [101]. Since this simple system, other more complex systems have been created [102]. Moreover, the development of genetic-engineering techniques has resulted in the creation of a wide range of elastin-based polymers with designs adapted to their final application. The transition temperature, type 
and number of cross-linking sites and the molecular weight of the ELR are all genetically encodable properties [12,29]. Thanks to our ability to vary the transition temperature, the vast majority of the ELR-based hydrogels developed for drug-delivery purposes have been created as injectable forms [29]. Injectable hydrogels display several important therapeutic advantages. For example, their implantation is characterized by a minimally invasive technique, thereby minimizing the tissue damage and pain associated with conventional surgical procedures. Additionally, this technique allows access to areas of the body that are otherwise difficult to reach and, with respect to the utilization of such hydrogels in the field of pharmacology, undesirable side effects associated with systemic drug delivery are reduced due to the specific and precise location. An injectable hydrogel must exhibit high fluidity at the time of injection and then undergoes a pronounced increase in its subsequent mechanical properties, thus resulting in the formation of a solid implant [103]. Appropriately designed ELRs fulfill both these requirements as they display a liquid-like state below the transition temperature, thus allowing injection and making their mixture with drugs efficient and extremely simple [104], and they can form a depot either by exploiting the hydrophobic interactions that take place above their Tt or by chemical bonds due to a previous specific modification of the ELR. For example, regarding the design of ELR-based hydrogels cross-linked by covalent bonds, Chilkoti's group has synthesized a battery of ELRs that differ from each other in the frequency of cysteine and the degree of hydrophobicity. These polymers are able to form disulfide cross-linked hydrogels in a matter of minutes under mildly oxidising conditions [105] and only non-toxic reagents are required during hydrogel formation. In another interesting approach, the high degree of transglutaminase specificity has been exploited to create a covalent cross-linked injectable hydrogel for cartilaginous applications [106]. Despite this, such examples remain an exception in the field of covalently cross-linked hydrogels as the preparation of most such gels requires extreme conditions, such as exposure to organic solvents, heat or high polymer concentrations [106-108], thus limiting their in vivo application.

In order to avoid the toxicity associated with most forms of chemical cross-linking, especially for gels designed to be formed in situ, various strategies for the formation of physical hydrogels have been developed. Thus, a second approach exploits their ITT behavior, which is characteristic of these polymers, as a means of achieving the formation of physical cross-links. To this end, ELRs are designed as amphiphilic multi-block co-polymers with alternating hydrophilic and hydrophobic blocks in such a way that hydrophobic aggregation occurs below $37{ }^{\circ} \mathrm{C}$ in an aqueous solvent. This means that when the polymer is injected, it senses the body temperature and the hydrophobic blocks interact physically with each other, thus giving rise to the cross-linking [109-111]. As an example, Sallach et al. have prepared a triblock corecombinamer in which a hydrophilic block $\left(\mathrm{Tt}>37^{\circ} \mathrm{C}\right)$ is flanked by two hydrophobic end blocks $\left(\mathrm{Tt}=18^{\circ} \mathrm{C}\right)$. This amphiphilic protein shows a minimal inflammatory response and robust stability for periods exceeding one year [34, 37]. In another interesting example, an ELR with a subphysiological $\mathrm{Tt}$ of $28^{\circ} \mathrm{C}$ conjugated to a radionuclide was been shown to form a local depot upon in vivo intratumoral injec- tion; a subsequent reduction in tumor growth was detected [110].

One of the main drawbacks of physical ELR-based hydrogels is the relatively weak nature of the physical interaction mediated by the hydrophobic domains of the elastomeric motifs. Several new alternatives have been explored to overcome this problem. Thus, a further step in the design of multiblock ELRs for the formation of physical hydrogels involves using cross-linking domains from peptide motifs other than elastin [99]. For example, silk fibroin domains, the primary sequence of which follows patterns such as GAGAGS, GAGAGY and GAGAGVGY, have been incorporated into the peptide backbone of the ELR, thus giving rise to so-called SELPs (silk elastin-like polymers) [112]. SELP-based hydrogels display better mechanical properties than their ELR-based counterparts due to the stability and irreversibility provided by the presence of the silk motifs, which adopt a characteristic anti-parallel $\beta$-sheet secondary structure [113]. SELP hydrogels have been found to exhibit in vivo biocompatibility since no clinical signs of toxicity were observed up to one month after intradermal or subcutaneous injection [114]. As is the case with ELR-polymer solutions, SELP ones can be mixed with drugs, thus allowing homogenous entrapment of the compound once the gelling process occurs. Thus, the release profiles for different compounds, such as cytochrome c, theophylline, vitamin B12, the recombinant protein mitotoxin and several fluorescently labeled probes, have been explored and several parameters, such as the molecular weight of the drug, the concentration of the SELP and its specific composition, have been found to influence drug release $[114,115]$. The application of SELPs has not been limited exclusively to drug carriers as their use for the localized matrix-mediated delivery of viral vectors has also been explored. For example, an SELP matrix embedded with an adenovirus containing both thymidine kinase- 1 and luciferase genes has been intratumorally injected into a nude mouse model of head and neck tumor, thus resulting in a fivefold reduction in tumor volume with respect to intra-tumoral injection of adenovirus in saline. Moreover, whereas expression in the animal injected with the SELP-based virus was confined to the tumor site, $50 \%$ of animals treated with the virus in saline showed liver dissemination [116]. In order to further assess the safety of this viral delivery system, a non-tumor bearing immunocompetent mouse model was used. The ability of the mice to regain their normal weight and blood count was assessed, and it was shown that matrix-mediated gene delivery with the SELP offers a significant reduction in toxicity compared to the injection of free virus [117].

\section{ELR Self-Assembly into Spherical Particles for Drug Delivery}

The ability of some ELRs to self-assemble to form nanoand micro-objects with spherical shapes has been used to achieve drug encapsulation. For example, microparticles has been obtained from both the chemical $[118,119]$ and recombinant [120] versions of poly(VPAVG), with the latter having the subsequent advantage of forming a strictly monodisperse material. The presence of alanine in the third position gives the polymer a hysteresis behavior: polymer selfassembly occurs above a $\mathrm{Tt}$ of $30^{\circ} \mathrm{C}$ but the self-assembled 
structures only solubilize again when a strong cooling of 12$15^{\circ} \mathrm{C}$ is achieved [118]. This makes the polymer particles easy to use since, once formed, they are stable unless a strong undercooling occurs. Recombinant spherical particles have been used to entrap bone morphogenetic proteins (BMPs) with high efficiency, with sustained release over 14 days in a bioactive way being observed. Moreover, no cytotoxicity was observed, thus corroborating the biocompatible character of these polymers [120].

Numerous studies of the behavior of amphiphilic multiblock ELRs have provided clear evidence for the tendency of such molecules to self-assembly into stable nano- and microparticles when the temperature is raised above the $\mathrm{Tt}$ of the polymer [121, 122]. For example, Chilkoti's group has designed and synthesized a battery of ELRs that selfassemble into micelles in the presence of a physiologically relevant trigger, such as a hyperthermic temperature in the range $37-42^{\circ} \mathrm{C}$ [123]. In a subsequent step, these ELR block copolymers were functionalized with the peptide ligand NGR (a vascular targeting agent). The micelles formed by this copolymer displayed higher cellular uptake than both the monomer form with the NGR and the micelle form without the NGR ligand. Additional examples of exploiting this thermosensitive behavior for application in cancer therapy by applying local hyperthermia will be discussed further in the next section since in such cases the ELR experiences a thermal transition and also plays an active role in targeting the site of action.

The inherent ability of amphiphilic ELRs to selfassemble into spherical particles has also been exploited in the field of immunology. One of the most recent publications in this sense describes the production of a vaccine carrier in which an amphiphilic ELR is co-expressed with an antigenic peptide from a major membrane protein present in $M$. tuber- culosis (Fig. 3) [124]. Above the $\mathrm{Tt}$, the fusion construct self-assembles into a nanovesicle of $60 \mathrm{~nm}$ (similar to the size of many pathogens) in which the antigenic motif is displayed at the surface. Such nanovesicles have been proven to be biocompatible, multivalent, monodisperse and stable for up to a year in solution, and are able to induce the secretion of chemotactic cytokines in vivo. This immune response is characterized by the early secretion of IL- $1 \beta$ (involved in the innate immune phase) followed by the induction of a Th-2 immune response, as shown by the late onset of IL- 5 production and the up-regulation of specific $\operatorname{IgM}$ and $\operatorname{IgG}$ antibody responses.

In a different approach, therapeutic containers composed of chitosan and an ELR were constructed using an LbL technique [86]. The resulting microcapsules displayed interesting properties as regards their potential use as drug carriers since the release profile of the model protein BSA was found to be dependent on the number of layers in the capsule architecture and on permeability variations due to the temperature response of the ELR, thus demonstrating promising features for protein delivery applications (Fig. 4).

\section{Further Use of ELRs in Drug Delivery}

The use of ELRs for controlled drug delivery is not restricted to hydrogels or capsules that entrap the drug. Thus, ELRs can be linked to synthetic drugs or active proteins chemically or using genetic engineering techniques, respectively. In such constructs, the ELR works as a tag that exerts diverse functions [18].

For example, many pharmaceutical compounds exhibit short half-lives since their small size allows rapid glomerular filtration. One solution to this comprises binding these compounds to ELRs in order to increase their size

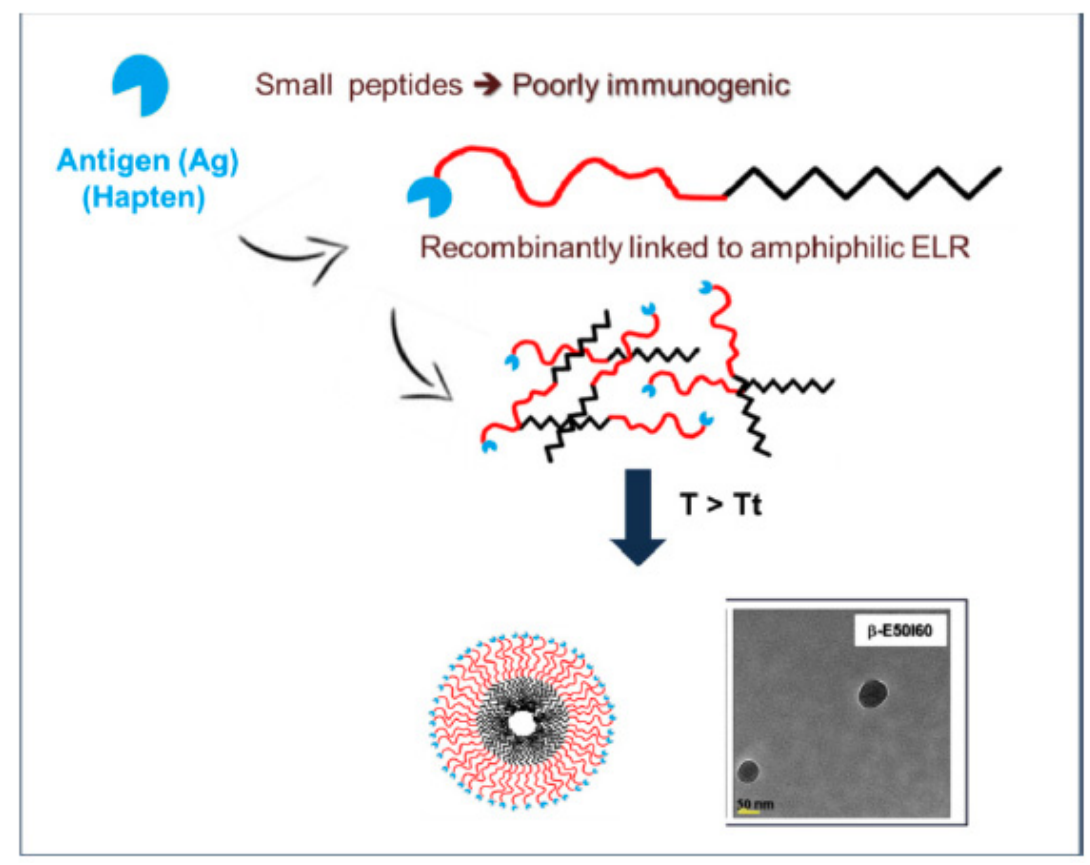

Fig. (3). Self-assembly of the ELR into spherical nanoparticles displaying a corona of antigens from a M. tuberculosis major membrane protein. Cryo-TEM image shows the morphological property of the assembly [124]. Adapted with permission from reference [115]. 

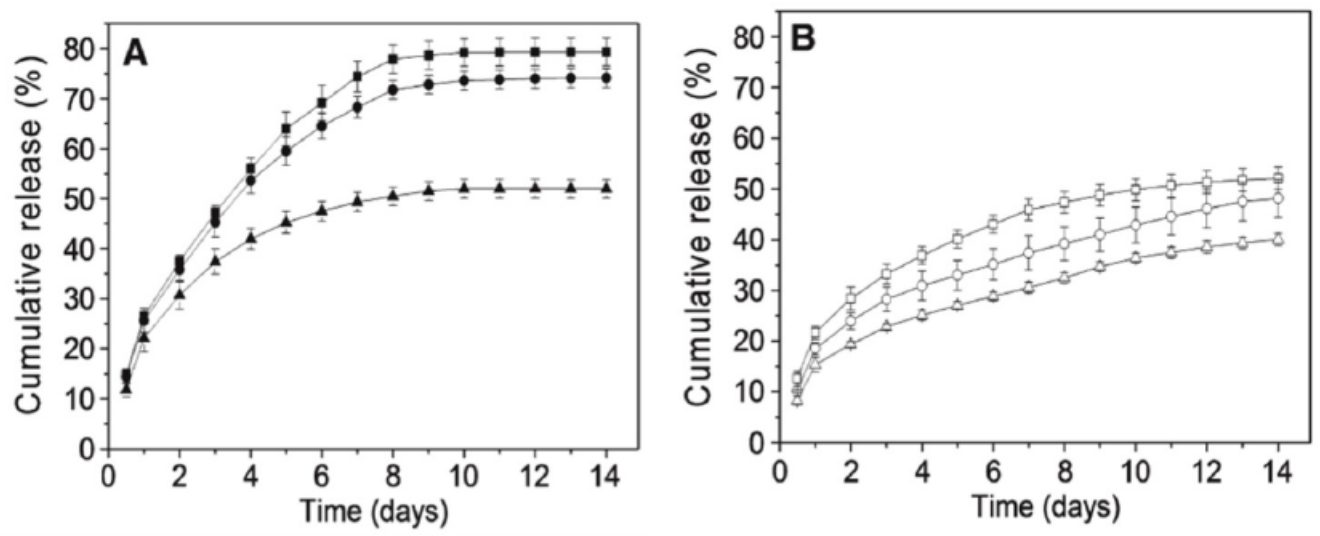

Fig. (4). Cumulative release of BSA from (Chi/ELR)1, (Chi/ELR)3 and (Chi/ELR)5 microcapsules: $\square$, $\bullet \bullet$, and $\Delta \Delta$, respectively, in PBS (pH 7.4) at (A) $25^{\circ} \mathrm{C}$ and (B) $37^{\circ} \mathrm{C}$. Reproduced with permission from reference [86].

[109, 125-127]. In this respect, a fusion construct comprising a single monoclonal antibody domain that recognizes TNF (TNF-VhH) and an ELR has been reported [127]. The serum half-life of the ELR-TNF-VhH protein was 24-fold longer than that of the naked antibody fragment and it displayed a comparable biological activity.

The tactic of increasing the size of the drug by incorporating an ELR has also proved useful in some anticancer strategies. One major drawback of many potential anticancer compounds is that only a small percentage of the dose administered reaches the tumor site. In order to improve the directionality of therapeutic treatment, several approaches that attempt to exploit two peculiarities of tumor tissues, namely the enhanced permeability and retention (EPR) effect [128] and the poor heat dissipation characteristics displayed by tumor tissues, which means that the application of localized hyperthermia leads to an increase in temperature in the diseased tissue, are being developed. Thus, as a result of the EPR effect, the size increase resulting from attachment of the drug to the ELR allows the construct to more readily penetrate and preferentially accumulate in tumors rather than in normal tissues. Moreover, the presence of the ELR in the construct makes it sensitive to applied local hyperthermia, thus meaning that the drug selectively accumulates in tumors [129]. Since the active molecule is not always protein-based, chemical modifications to the ELR in order to create reactive sites for drug-conjugation purposes are needed. For example, a doxorubicin-based drug has been attached to an ELR in order to achieve targeted delivery to solid tumors as a result of the inverse temperature transition behavior of the elastomeric polymer [130]. Despite the accumulation of macromolecules in tumor tissue due to the EPR effect, an additional obstacle remains: the plasma membrane. Cellular internalization has been improved by the use of cell penetrating peptides (CPPs). CPPs are short peptides that are able to pass through the plasma membrane and enter the cytoplasm [131]. In light of these considerations, doxorubicin delivery has also been explored by designing an ELR-based doxorubicin delivery system incorporating a CPP derived from HIV-1 Tat protein $[132,133]$. Thus, the doxorubicin delivery construct containing the Tat protein, an ELR, a lysosomally degradable spacer and a cysteine residue conjugated to a thiol-based doxorubicin derivative undergoes a phase transition at $40^{\circ} \mathrm{C}$ and its internalization by cells can be enhanced using both the CPP and its hyperthermia-induced phase transition. Along similar lines, a peptide derivative of bovine lactoferrin (L12) has been fused to a Tat-ELR construct using genetic engineering tools. The final chimeric Tat-ELRL12 protein showed a marked ability to thermally target cancer cells and to inhibit their proliferation by between $60 \%$ and $90 \%$, depending on the cell line [134]. Another very interesting example of the combined use of ELR and CPPs to enhance cell uptake has been describe by Chilkoti's group [135]. Assuming that the penetration ability of oligo-arginine CPPs depends on the local arginine density, a construct in which the ELR acts as a modulator of the interfacial density of such residues was constructed. Thus, below the specific $\mathrm{Tt}$, which was tuned to be in the range $39-42{ }^{\circ} \mathrm{C}$, the ELR fused with the oligo-arginine-based CPP $\left(\mathrm{Arg}_{5}-\mathrm{ELR}_{\mathrm{BC}}\right)$ exists as a soluble monomer. Micelle self-assembly to give a corona composed of the arginine residues is triggered by applying mild clinical hyperthermia. An eightfold difference in cellular uptake was found between the $\mathrm{Arg}_{5}-\mathrm{ELR}_{\mathrm{BC}}$ and both $\mathrm{ELR}_{\mathrm{BC}}$ (without the arginines) and $\mathrm{Arg}_{5}$-ELR (where the ELR is highly hydrophilic). Therefore, a system which displays an "off-on" cellular uptake as a consequence of differences in local Arg density between the monomer and the micelle has been created [135].

Despite the numerous examples that have already appeared in the literature, a large number of design possibilities for controlled drug delivery still remain. The ultimate aim should be the formation of a vehicle that is able to sense a chemical abnormality in diseased tissue and release the drug in response to it in order to correct the imbalance. The achievement of such a system would be the ultimate objective of drug delivery as it would be able to act in a similar manner to the body, which exercises close control over the release and distribution of its own endogenous biological agents. Elastin-based polymers are an interesting option to make progress towards this goal due to their ability to sense their environment and respond to changes in it. A more indepth understanding of the relationship between the structure and function of these polymers will lead to the development of systems that are able to sense specific physicochemical changes associated with diseased tissue and trigger a response. The development of such systems is also assisted by their recombinant character, which allows polymer design to be adapted to the desired application with extraordinary ac- 
curacy. The examples mentioned above demonstrate a strong commitment to attaining this goal.

\section{NANOTECHNOLOGICAL APPLICATIONS OF ELRS}

Since nanotechnology was first discussed in 1959 by Richard Feynman, its study and applications have been continuously growing in all branches of science. Two major nanotechnological fields, namely diagnostic and biosensing techniques and nanoparticle-based drug/gene/protein delivery, are especially important for biomedicine.

Apart from the properties mentioned previously in this review, which make them ideal candidates for biomedical applications, elastin-like recombinamers are also highly interesting materials from a nanotechnological point of view due to their recombinant nature and ability to self-assemble [136]. In this section we will focus on the recent confluence of nanotechnology and ELRs in the context of both conjugation with inorganic materials and self-assembled nanostructures.

\section{Hybrid Metal- and Semiconductor-ELR Materials}

Metal nanoparticles such as gold, copper or silver have attracted the attention of many researchers in the past few years due to their unique optical and electronic properties, which depend strongly on their size and shape [137-139].

Gold nanoparticles are of particular interest for biomedical applications because of their near-infrared absorption properties [140] and high surface area to volume ratio, which make them good candidates as drug carriers [141] or photothermal agents [142]. However, gold nanoparticles are unstable and prone to irreversibly aggregate. As such, in order to increase their stability and provide environmental responsiveness (such as to $\mathrm{pH}$ or temperature), gold nanoparticles have been conjugated to ELRs [16, 143-145].

Alvarez-Rodriguez et al. [143] have developed a one-pot method for synthesizing smart ELR-gold nanoparticle hybrid materials using a $\mathrm{pH}$ - and temperature-sensitive glutamic acid-based ELR (Glu15). This reaction is carried out in one step by the aqueous reduction of auric acid in the presence of Glu15 and an excess of reducing agent. This excess is employed in order to avoid the formation of ionic gold species. Direct visualization by TEM revealed rounded nanoparticles with a diameter of between 2 and $11 \mathrm{~nm}$ that present thermosensitive properties at acid $\mathrm{pH}$ as a result of cluster aggregation at $40^{\circ} \mathrm{C}$ and an expansion at $4^{\circ} \mathrm{C}$. This structure reversibility leads to different light absorbance properties, thereby opening up the possibility of modulating light absorption, which is of great interest in bio-sensing or photothermal therapies.

Silver has also been investigated in the biomedical field, especially due to its antibacterial properties, although its cytotoxicity and genotoxicity hinder its possible usage. Conjugation with a highly biocompatible material such as an ELR may solve this issue. In this sense, Anh et al. have designed a new ELR that is able to nucleate silver after being incubated in silver nitrate, thus conferring antibacterial properties on the recombinamer [146].

Semiconductor nanocrystals, also known as quantum dots (QDs), have very interesting properties for biomedical applications, such as high quantum yield, narrow cations, such as high quantum yield, narrow fluorescence emission, broad absorption profile and stability against photobleaching [147]. However, QDs are nonpolar and therefore insoluble in aqueous media, thus making them incompatible for most biomedical applications. Furthermore, QDs are usually made of heavy metal ions, with the high toxicity that this implies. In order to overcome these drawbacks, QDs must be conjugated with other molecules that provide them with the properties they require for biomedical use. In this sense, Lao et al. have described an antibody-quantum dot (CdSE-ZnS) complex that uses an ELR as scaffold [1481. These authors constructed a fusion recombinant protein in which the model ELR (VPGVG) ${ }_{78}$ is flanked by a polyhistidine tag at the $\mathrm{N}$ terminus (for conjugation with the QDs via $\mathrm{Zn}^{2+}$ ) and a protein $\mathrm{L}$ sequence (an antibody binding protein) at the $\mathrm{C}$ terminus. The role of this ELR is to confer the fusion protein with thermoresponsive behavior, which is a key parameter for complex purification. The resulting fusion ELR protein was used as an effective inmunofluorescent agent for antibody array analysis. In order to test it, the representative carcinoembryonic tumor marker antigen was chosen.

Fahmi et al. subsequently described the manufacture of CdSe-ELR nanofibers [149]. These authors designed a simple route for the manufacture of these nanofibers in aqueous solution that takes advantage of the self-assembly properties of a glutamic acid-containing elastin-like recombinamer. Thus, CdSe nanoparticles were prepared by complexation of $\mathrm{Cd}^{\mathrm{II}}$ to the glutamate, followed by selenization with $\mathrm{NaHSe}$ in an aqueous medium. During generation of the semiconducting nanoparticles, the ELR/CdSe nanoparticles selfassemble into nanofibers, at neutral $\mathrm{pH}$, due to electrostatic interactions.

The ELR stabilizes the CdSe nanoparticles and controls their nucleation, growth and spatial distribution in a process that is strongly dependent on the $\mathrm{pH}$ of the medium due to the presence of carboxylate groups on the heterogeneously charged polypeptide shell. The effect of $\mathrm{pH}$ is shown in Fig. 5: At acid pH, the shell is completely apolar, thus leading to the formation of agglomerates, whereas upon increasing the $\mathrm{pH}$, the carboxy groups become ionized, thereby reducing their tendency to agglomerate and resulting in elongated lace-like structures $(\mathrm{pH} 4.8)$ and nanofibers $(\mathrm{pH} 7.2)$. Complete disruption of the fibers occurs at $\mathrm{pH} 10$.

The cytotoxicity of these nanofibers was tested using B14 fibroblast cells. They were found to be nontoxic and able to cross the cell membrane barrier, thus making them promising materials for future medical nanotechnology applications, such as the diagnosis and treatment of various diseases.

In 2010, the Nobel Prize in Physics was awarded to Konstantin Novoselov and Andre Geim "for groundbreaking experiments regarding the two-dimensional material graphene". Graphene is widely expected to prove to be a revolutionary material in the near future due to its outstanding properties, some of which, such as its high surface area, near-infrared energy absorption or highly sensitive electrical properties, are also suitable for the biomedical field and use in biomedical applications such as tumor photothermal therapy, cellular imaging, drug delivery or platforms for stem 


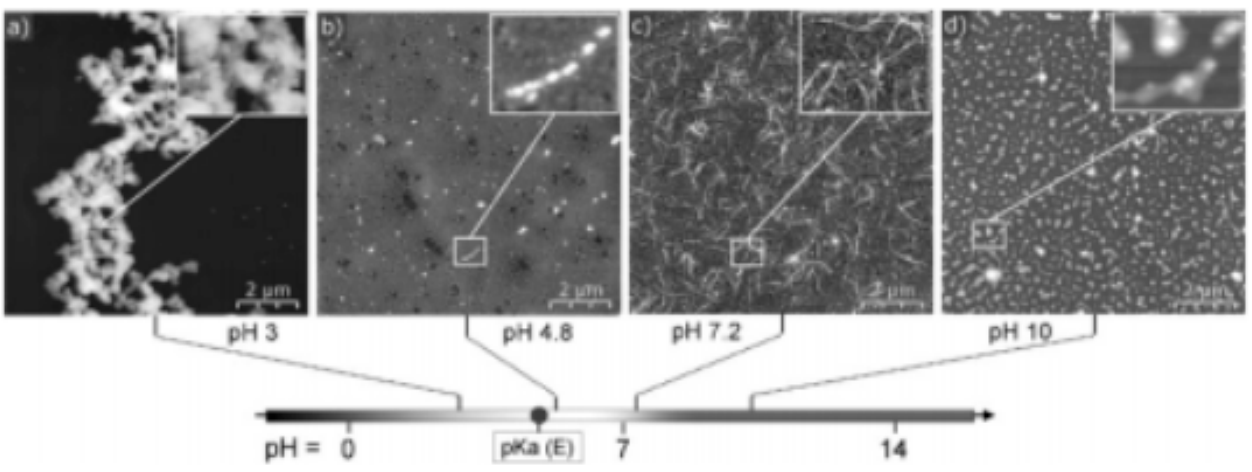

Fig. (5). AFM height images showing the effect of pH on the morphology of self-assembled ELR-CdSe nanostructures. Reproduced with permission from reference [149].

cell differentiation [150-153]. However, as we have seen previously for other materials, graphene, or graphene oxide, present two mayor drawbacks, namely their poor solubility and toxicity. To overcome this problem, graphene is being conjugated to other molecules, such as ELRs, to increase its solubility and confer biocompatibility.

Wang et al. [154] have recently designed and produced the first graphene-ELR composite hydrogel using a fifty pentapeptide recombinamer $(\mathrm{VPGVG})_{50}$ followed by a graphene binding sequence (HNWYHWWPH). The hydrogels are irradiated with near-IR light to induce a local transition of the ELRs and produce bending motions, thus confirming the absorption of near-IR radiation and opening up the possibility of future studies of light-controlled dynamic cell culture or drug delivery.

\section{ELR-Based Nanostructures}

ELRs have been widely used as self-assembling materials that lead to the formation of nanoparticles. Recombinant DNA techniques have allowed block copolymers to be obtained with absolute control of the amino acid composition, thereby opening up the possibility of conferring the polymer with different responsiveness, such as $\mathrm{pH}$ [155], ionic concentration [17] and so on, simultaneously. To this end, ELRbased amphiphilic diblock and triblock copolymers have been synthesized in which the amphiphilicity $[123,156]$ of the component blocks is achieved by substituting the amino acid (X) in the guest position of the pentamer VPGXG by different hydrophilic (glutamic acid, aspartic acid or lysine) or hydrophobic (isoleucine or alanine) amino acids. Nanoparticle formation occurs when the elastin-like block co-recombinamer (ELbcRs) solution is heated above the characteristic $\mathrm{Tt}$ of the hydrophobic block, at which point the co-recombinamer chains organize themselves by hiding the hydrophobic blocks from the aqueous environment, thus reaching a minimum free energy situation.

The first example of such self-assembled nanoparticles found in the literature was reported as far back as 2000 by Lee et al. [23], who reported a di-block ELbcR construct that self-assembled under dilute basic conditions $(0.1 \mathrm{M} \mathrm{NaOH})$ into a narrow distribution of $90 \mathrm{~nm}$ micelles, and upon increasing the concentration into worm-like micelles due to the aggregation of individual nanoparticles. Numerous other studies have been published since then in an attempt to shed light on the self-assembly of such elastin-like micelles [122,
$123,157]$. Other morphologies, such as vesicles, are much harder to obtain.

Dash et al. [158] have published an alternative to this self-assembly process that leads to the formation of hollow vesicles. These authors coated sulfonated polystyrene beads with an ELR, which gave them a negative charge, then crosslinked the ELRs using microbial transglutaminase (mTGase). Finally, the PS beads were dissolved using THF to provide hollow structures of different sizes $(100,300,500$ and $1000 \mathrm{~nm}$ ). These hollow spheres were loaded with polyplexes and naked pDNA and studied as nucleic acid delivery depot. More recently, Martín et al. obtained micelles and vesicles by the self-assembly of ELbcRs [156]. Three different polymers (E50A40, E50A40E50, and E100A40) in which the component blocks of the three recombinamers were the same but with different lengths and architectures were used. The authors claimed that the molecular architecture of the ELbcRs is a key parameter in determining the structure of the resulting self-assembled nanoparticles. E50A40 was found to adopt a $150 \mathrm{~nm}$ micellar structure, whereas $200 \mathrm{~nm}$ hollow vesicles were obtained using the other two recombinamers (Fig. 6).

Vesicles represent a great advance compared with micelles as, although the latter are perfect candidates for the encapsulation of hydrophobic molecules, vesicles allow the possibility of both entrapping such hydrophobic molecules and also using the inner cavity as a carrier for hydrophilic guest molecules such as therapeutic agents.

Although self-assembly is the most widely used technique for the fabrication of ELR nanoparticles, other techniques have been also reported. Thus, electrospraying [159] has been used to generate nanoparticles with diameters of about $300-400 \mathrm{~nm}$ by dissolving ELRs in trifluoroethanol and doxorubicin in a 25:1 trifluoroethanol/ethanol mixture. Two glutamic acid-containing ELRs with different molecular weights were studied. Glutamic acids were included in these sequences for two reasons: first, to provide a negative charge to the recombinamers in order to favor the formation of nanoparticles during electrospraying by Coulombic repulsion, and second, to confer $\mathrm{pH}$ responsiveness on them, thus allowing tuning of the $\mathrm{Tt}$ and thus delivery of the load depending on the $\mathrm{pH}$. The morphology was strongly affected by the molecular weight and concentration of the ELR, with a decrease in molecular weight resulting in a change from fibers and particles with a tail to spherical particles, which 

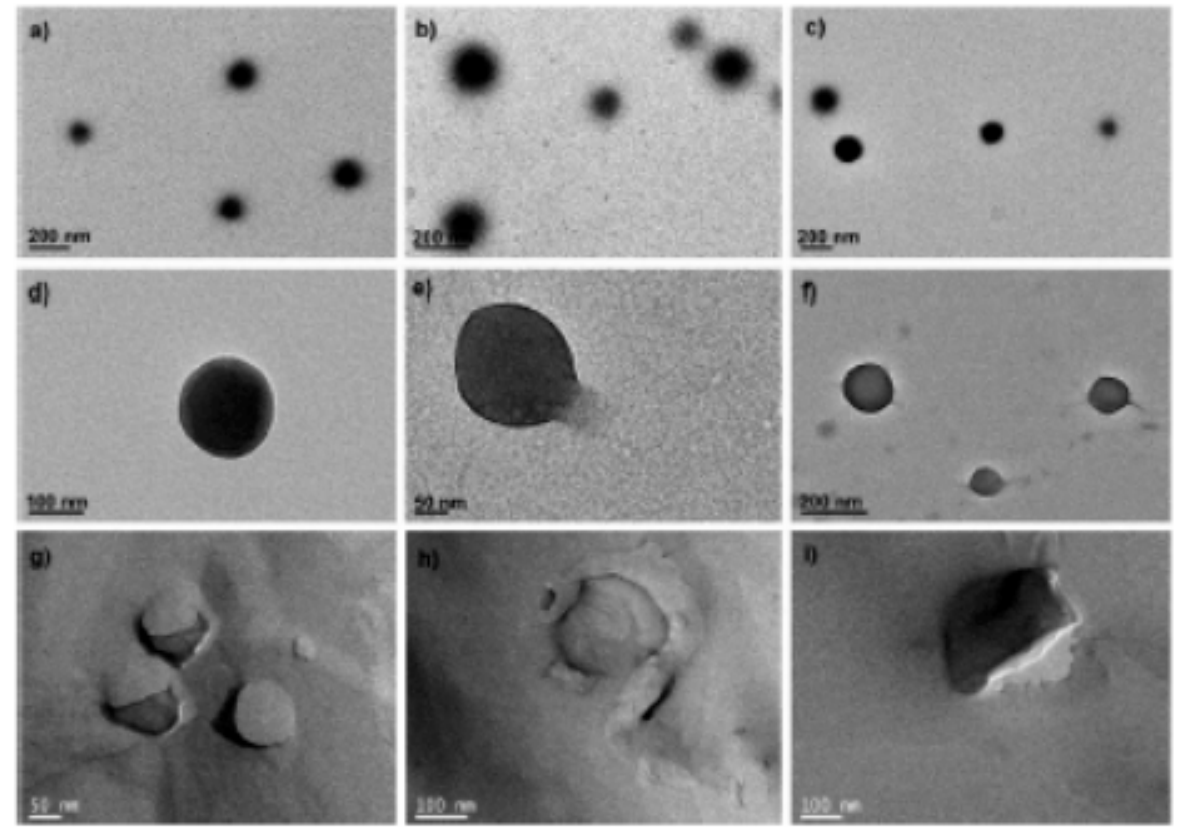

Fig. (6). TEM images of self-assembled nanoparticles without staining (top), stained (middle) with $1 \%$ uranyl acetate, and freezefractured (bottom): (a,d,g) E50A40, (b,e,h) E100A40, and (c,f,i) E50A40E50. E: Glutamic acid based block; A: Alanine based block. Reproduced with permission from reference [156].

were preferentially obtained using ELRs of a low molecular weight.

The ability of ELRs to self-assemble in response to changes in their environment makes them highly attractive materials for the fabrication of multiple nanostructures with different and varying morphologies. This self-assembly behavior, together with the ability to conjugate them to different inorganic materials, increases their importance and possible applications from a nanotechnological point of view.

\section{CONCLUSIONS}

Protein-based biomaterials have become increasingly common in the last few years due to the development of new molecular biology and genetic engineering techniques that allow their recombinant production in an extremely controlled and versatile manner. The excellent properties of natural elastin have propelled the development of recombinant versions of this protein-based polymer and have led to the so-called elastin-like recombinamers (ELR). This chapter has reviewed all the most important applications of ELRs, especially tissue engineering, surface engineering, drug delivery and the generation of nano-devices, thereby highlighting their enormous utility and potential in the fields of biomedicine and biotechnology.

\section{CONFLICT OF INTEREST}

The author(s) confirm that this article content has no conflicts of interest.

\section{ACKNOWLEDGEMENTS}

We acknowledge financial support from the EU via the European regional development fund (ERDF), MINECO (MAT-2010-15982, MAT2010-15310, PRI-PIBAR-2011-
1403 and MAT2012-38043), the JCyL (projects VA049A11, VA152A12 and VA155A12), CIBER-BBN, and JCyL and the Instituto de Salud Carlos III under the "Network Center of Regenerative Medicine and Cellular Therapy of Castilla and Leon". Authors thank A. Frankland for correcting the English version of the manuscript.

\section{REFERENCES}

[1] Hu, X.; Cebe, P.; Weiss, A. S.; Omenetto, F.; Kaplan, D. L.Proteinbased composite materials. Materials Today, 2012, 15, 208-215.

[2] Girotti, A.; Fernández-Colino, A.; López, I. M.; RodríguezCabello, J. C.; Arias, F. J.Elastin-like recombinamers: Biosynthetic strategies and biotechnological applications. Biotechnol. J. 2011, 6, 1174-1186.

[3] Rodríguez-Cabello, J.; Girotti, A.; Ribeiro, A.; Arias, F., Synthesis of Genetically Engineered Protein Polymers (Recombinamers) as an Example of Advanced Self-Assembled Smart Materials. Methods Mol. Biol. 2012, 811,17-38.

[4] MacEwan, S. R.; Chilkoti, A.Elastin-like polypeptides: Biomedical applications of tunable biopolymers. Pept. Sci. 2011, 94, 60-77.

[5] Rodríguez-Cabello, J. C.; Martín, L.; Alonso, M.; Arias, F. J.; Testera, A. M."Recombinamers" as advanced materials for the post-oil age. Polymer, 2009, 50, 5159-5169.

[6] Miao, M.; Bellingham, C. M.; Stahl, R. J.; Sitarz, E. E.; Lane, C. J.; Keeley, F. W.Sequence and structure determinants for the selfaggregation of recombinant polypeptides modeled after human elastin. J. Biol. Chem. 2003, 278, 48553-48562.

[7] Urry, D. W.; Hugel, T.; Seitz, M.; Gaub, H. E.; Sheiba, L.; Dea, J.; Xu, J.; Parker, T.Elastin: a representative ideal protein elastomer. Philos. Trans. R. Soc. Lond. B, 2002, 357, 169-184.

[8] Di Zio, K.; Tirrell, D. A.Mechanical properties of artificial protein matrices engineered for control of cell and tissue behavior. Macromolecules, 2003, 36, 1553-1558.

[9] Rodríguez-Cabello, J. C.; Reguera, J.; Girotti, A.; Arias, F. J.; Alonso, M.Genetic Engineering of Protein-Based Polymers: The Example of Elastin like Polymers. Adv. Polym. Sci. 2006, 200, 119167.

[10] Urry, D. W., What sustains life? Consilient mechanisms for protein-based machines and materials. Springer-Verlag: New York, 2006. 
[11] San Biagio, P. L.; Madonia, F.; Trapane, T. L.; Urry, D. W.The Overlap of Elastomeric Polypeptide Coils in Solution Required for Single-Phase Initiation of Elastogenesis. Chem. Phys. Lett. 1988, 145, 571-574.

[12] Ribeiro, A.; Arias, F. J.; Reguera, J.; Alonso, M.; RodriguezCabello, J. C.Influence of the amino-acid sequence on the inverse temperature transition of elastin-like polymers. Biophys. J. 2009, 97, 312-320

[13] Alvarez-Rodriguez, R.; Arias, F. J.; Santos, M.; Testera, A. M.; Rodriguez-Cabello, J. C.Gold Tailored Photosensitive Elastin-like Polymer: Synthesis of Temperature, $\mathrm{pH}$ and UV-vis Sensitive Probes. Macromol. Rapid Commun. 2010, 31, 568-573.

[14] Reguera, J.; Urry, D. W.; Parker, T. M.; McPherson, D. T.; Rodriguez-Cabello, J. C.Effect of $\mathrm{NaCl}$ on the Exothermic and Endothermic Components of the Inverse Temperature Transition of a Model Elastin-like Polymer. Biomacromolecules, 2007, 8, 354358 .

[15] Bochicchio, B.; Aït-Ali, A.; Tamburro, A. M.; Alix, A. J. P.Spectroscopic evidence revealing polyproline II structure in hydrophobic, putatively elastomeric sequences encoded by specific exons of human tropoelastin. Biopolymers, 2004, 73, 484-493.

[16] Tamburro, A. M.; Guantieri, V.; Pandolfo, L.; Scopa, A.Synthetic fragments and analogues of elastin. II. Conformational studies. Biopolymers, 1990, 29, 855-870.

[17] Debelle, L.; Alix, A. J. P.Optical spectroscopic determination of bovine tropoelastin molecular model. J Mol Struct, 1995, 348, 321324.

[18] MacEwan, S. R.; Chilkoti, A.Elastin-like polypeptides: biomedical applications of tunable biopolymers. Biopolymers, 2010, 94, 60-77.

[19] Macewan, S. R.; Chilkoti, A.Elastin-like polypeptides: Biomedical applications of tunable biopolymers. Biopolymers, 94, 60-77.

[20] Nettles, D. L.; Chilkoti, A.; Setton, L. A.Applications of elastinlike polypeptides in tissue engineering. Adv. Drug Deliv. Rev. 2010, 62, 1479-1485.

[21] McDaniel, J. R.; Callahan, D. J.; Chilkoti, A.Drug delivery to solid tumors by elastin-like polypeptides. Adv. Drug Deliv. Rev. 2010, 62, 1456-1467.

[22] Huang, L.; McMillan, R. A.; Apkarian, R. P.; Pourdeyhimi, B.; Conticello, V. P.; Chaikof, E. L.Generation of Synthetic ElastinMimetic Small Diameter Fibers and Fiber Networks. Macromolecules, 2000, 33, 2989-2997.

[23] Lee, T. A. T.; Cooper, A.; Apkarian, R. P.; Conticello, V. P.Thermo-reversible self-assembly of nanoparticles derived from elastin-mimetic polypeptides. Adv. Mater. 2000, 12, 1105-1110.

[24] Rodríguez-Cabello, J.C.; Prieto, S.; Arias, F.J.; Reguera, J.; Ribeiro, A. Nanobiotechnological approach to engineered biomaterial design: the example of elastin-like polymers. Nanomedicine (London, U. K.) 2006, 1, 267-280.

[25] Kim, T. G.; Shin, H.; Lim, D. W.Biomimetic Scaffolds for Tissue Engineering. Adv. Funct. Mater. 2012, 22, 2446-2468.

[26] Luan, C.-H.; Urry, D. W., Elastic, Plastic, and Hydrogel Proteinbased Polymers. In Polymer Data Handbook, Mark, J. E., Ed. Oxford University Press: New York, 1999; pp 78-89.

[27] Martin, L.; Alonso, M.; Moller, M.; Rodriguez-Cabello, J. C.; Mela, P.3D microstructuring of smart bioactive hydrogels based on recombinant elastin-like polymers. Soft Matter, 2009, 5, 15911593.

[28] Martin, L.; Javier Arias, F.; Alonso, M.; Garcia-Arevalo, C.; Rodriguez-Cabello, J. C.Rapid micropatterning by temperaturetriggered reversible gelation of a recombinant smart elastin-like tetrablock-copolymer. Soft Matter, 2010, 6, 1121-1124.

[29] McDaniel, J. R.; Radford, D. C.; Chilkoti, A.A Unified Model for De Novo Design of Elastin-like Polypeptides with Tunable Inverse Transition Temperatures. Biomacromolecules, 2013, 14, 28662872.

[30] Sbrana, F.; Fotia, C.; Bracalello, A.; Baldini, N.; Marletta, G.; Ciapetti, G.; Bochicchio, B.; Vassalli, M. Multiscale characterization of a chimeric biomimetic polypeptide for stem cell culture. Bioinspiration Biomimetics, 2012, 7, 1-9.

[31] Nicol A, G. D., Parker TM, Urry DW Cell adhesive properties of bioelastic materials containing cell attachment sequences. Plenum Press.: New York, 1994.

[32] Nagaoka, M.; Jiang, H.-L.; Hoshiba, T.; Akaike, T.; Cho, C.S.Application of Recombinant Fusion Proteins for Tissue Engineering. Ann. Biomed. Eng. 2010, 38, 683-693.
[33] Nagapudi, K.; Brinkman, W. T.; Thomas, B. S.; Park, J. O.; Srinivasarao, M.; Wright, E.; Conticello, V. P.; Chaikof, E. L.Viscoelastic and mechanical behavior of recombinant protein elastomers. Biomaterials, 2005, 26, 4695-4706.

[34] Sallach, R. E.; Cui, W.; Wen, J.; Martinez, A.; Conticello, V. P.; Chaikof, E. L.Elastin-mimetic protein polymers capable of physical and chemical crosslinking. Biomaterials, 2009, 30, 409-422.

[35] Lim, D. W.; Nettles, D. L.; Setton, L. A.; Chilkoti, A.In situ crosslinkinig of elastin-like polypeptide block copolymers for tissue repair. Biomacromolecules, 2008, 9, 222-230.

[36] Betre, H.; Ong, S. R.; Guilak, F.; Chilkoti, A.; Fermor, B.; Setton, L. A.Chondrocytic differentiation of human adipose-derived adult stem cells in elastin-like polypeptide. Biomaterials, 2006, 27, 9199.

[37] Sallach, R. E.; Cui, W.; Balderrama, F.; Martinez, A. W.; Wen, J.; Haller, C. A.; Taylor, J. V.; Wright, E. R.; Long, R. C., Jr.; Chaikof, E. L.Long-term biostability of self-assembling protein polymers in the absence of covalent crosslinking. Biomaterials, 2010, 31, 779-791.

[38] Ravi, S.; Caves, J. M.; Martinez, A. W.; Haller, C. A.; Chaikof, E. L.Incorporation of fibronectin to enhance cytocompatibility in multilayer elastin-like protein scaffolds for tissue engineering. $J$. Biomed. Mater. Res. A, 2013, 101A, 1915-1924.

[39] Stevens, M. M.; George, J. H.Exploring and engineering the cell surface interface. Science, 2005, 310, 1135-1138.

[40] Bae, J.; Goto, S.; Mie, M.; Kobatake, E.Construction of a thermostable cell adhesion protein for reverse transfection. $J$. Biotechnol. 2010, 150, 447-451.

[41] Assal, Y.; Mie, M.; Kobatake, E.The promotion of angiogenesis by growth factors integrated with ECM proteins through coiled-coil structures. Biomaterials, 2013, 34, 3315-3323.

[42] Nakamura, M.; Mie, M.; Nakamura, M.; Kobatake, E.Construction of multi-functional extracellular matrix proteins that inhibits migration and tube formation of endothelial cells. Biotechnol. Lett. 2012, 34, 1571-1577.

[43] Prieto, S.; Shkilnyy, A.; Rumplasch, C.; Ribeiro, A.; Arias, F. J.; Carlos Rodriguez-Cabello, J.; Taubert, A.Biomimetic Calcium Phosphate Mineralization with Multifunctional Elastin-Like Recombinamers. Biomacromolecules, 2011, 12, 1480-1486.

[44] Yannas, I. V.Emerging rules for inducing organ regeneration. Biomaterials, 2013, 34, 321-330.

[45] Garcia-Arevalo, C.; Pierna, M.; Girotti, A.; Arias, F. J.; RodriguezCabello, J. C.A comparative study of cell behavior on different energetic and bioactive polymeric surfaces made from elastin-like recombinamers. Soft Matter, 2012, 8, 3239-3249.

[46] Straley, K. S.; Heilshorn, S. C.Design and adsorption of modular engineered proteins to prepare customized, neuron-compatible coatings. Front Neuroeng, 2009, 2.

[47] Liu, J.; Tirrell, D.Cell response to RGD density in cross-linked artificial extracellular matrix protein films. Biomacromolecules, 2008, 9, 2984-2988.

[48] Ozturk, N.; Girotti, A.; Kose, G. T.; Rodriguez-Cabello, J. C.; Hasirci, V.Dynamic cell culturing and its application to micropatterned, elastin-like protein-modified poly(Nisopropylacrylamide) scaffolds. Biomaterials, 2009, 30, 5417-5426.

[49] Chung, C.; Anderson, E.; Pera, R. R.; Pruitt, B. L.; Heilshorn, S. C.Hydrogel crosslinking density regulates temporal contractility of human embryonic stem cell-derived cardiomyocytes in 3D cultures. Soft Matter, 2012, 8, 10141-10148.

[50] Punet, X.; Mauchauffe, R.; Giannotti, M. I.; Rodriguez-Cabello, J. C.; Sanz, F.; Engel, E.; Mateos-Timoneda, M. A.; Planell, J. A.Enhanced Cell-Material Interactions through the Biofunctionalization of Polymeric Surfaces with Engineered Peptides. Biomacromolecules, 2013, 14, 2690-2702.

[51] Choi, S. K.; Park, J. K.; Lee, K. M.; Lee, S. K.; Jeon, W. B.Improved neural progenitor cell proliferation and differentiation on poly(lactide-co-glycolide) scaffolds coated with elastin-like polypeptide. J. Biomed. Mater. Res. B Appl. Biomater. 2013, 101B, 1329-1339.

[52] Lampe, K. J.; Antaris, A. L.; Heilshorn, S. C.Design of threedimensional engineered protein hydrogels for tailored control of neurite growth. Acta Biomater. 2013, 9, 5590-5599.

[53] Lee, K.-M.; Jung, G.-S.; Park, J.-K.; Choi, S.-K.; Jeon, W. B.Effects of Arg-Gly-Asp-modified elastin-like polypeptide on pseudoislet formation via up-regulation of cell adhesion molecules 
and extracellular matrix proteins. Acta Biomater. 2013, 9, 56005608.

[54] Tejeda-Montes, E.; Smith, K. H.; Rebollo, E.; Gomez, R.; Alonso, M.; Rodriguez-Cabello, J. C.; Engel, E.; Mata, A.Bioactive membranes for bone regeneration applications: effect of physical and biomolecular signals on mesenchymal stem cell behaviour. Acta Biomater. 2013, 10, 134-141.

[55] Ciofani, G.; Genchi, G. G.; Liakos, I.; Athanassiou, A.; Mattoli, V.; Bandiera, A.Human recombinant elastin-like protein coatings for muscle cell proliferation and differentiation. Acta Biomater. 2013, 9, 5111-5121.

[56] Kinikoglu, B.; Carlos Rodriguez-Cabello, J.; Damour, O.; Hasirci, V.A smart bilayer scaffold of elastin-like recombinamer and collagen for soft tissue engineering. J. Mater. Sci: Mater. Med. 2011, 22, 1541-1554.

[57] Kinikoglu, B.; Carlos Rodriguez-Cabello, J.; Damour, O.; Hasirci, $\mathrm{V}$.The influence of elastin-like recombinant polymer on the selfrenewing potential of a $3 \mathrm{D}$ tissue equivalent derived from human lamina propria fibroblasts and oral epithelial cells. Biomaterials, 2011, 32, 5756-5764.

[58] Srivastava, G. K.; Martin, L.; Singh, A. K.; Fernandez-Bueno, I.; Gayoso, M. J.; Garcia-Gutierrez, M. T.; Girotti, A.; Alonso, M.; Rodriguez-Cabello, J. C.; Pastor, J. C.Elastin-like recombinamers as substrates for retinal pigment epithelial cell growth. J. Biomed. Mater. Res. A, 2011, 97A, 243-250.

[59] Singh, A. K.; Srivastava, G. K.; Martín, L.; Alonso, M.; Pastor, J. C.Bioactive substrates for human retinal pigment epithelial cell growth from elastin-like recombinamers. J. Biomed. Mater. Res. A, 2013, DOI: $10.1002 /$ jbm.a.34726

[60] Heilshorn, S. C.; Liu, J. C.; Tirrell, D. A.Cell-binding domain context affects cell behavior on engineered proteins. Biomacromolecules, 2005, 6, 318-323.

[61] Liu, J. C.; Heilshorn, S. C.; Tirrell, D. A.Comparative cell response to artificial extracellular matrix proteins containing the RGD and CS5 cell-binding domains. Biomacromolecules, 2004, 5, 497-504.

[62] Plouffe, B. D.; Njoka, D. N.; Harris, J.; Liao, J.; Horick, N. K.; Radisic, M.; Murthy, S. K.Peptide-mediated selective adhesion of smooth muscle and endothelial cells in microfluidic shear flow. Langmuir, 2007, 23, 5050-5055.

[63] Garcia, Y.; Hemantkumar, N.; Collighan, R.; Griffin, M.; Rodriguez-Cabello, J. C.; Pandit, A.In vitro characterization of a collagen scaffold enzymatically cross-linked with a tailored elastinlike polymer. Tissue Eng. Part A, 2009, 15, 887-899.

[64] Spector, M.An interview with I V Yannas. Tracing one of the deepest roots of biomaterials in tissue engineering/regenerative medicine. Biomed. Mater. 2013, 8, 040401.

[65] Girotti, A.; Reguera, J.; Rodríguez-Cabello, J. C.; Arias, F. J.; Alonso, M.; Testera, A. M.Design and bioproduction of a recombinant multi(bio)functional elastin-like protein polymer containing cell adhesion sequences for tissue engineering purposes. J. Mater. Sci: Mater. Med. 2004, 15, 479-484.

[66] Straley, K. S.; Heilshorn, S. C.Independent tuning of multiple biomaterial properties using protein engineering. Soft Matter, 2009, 5, 114-124.

[67] Martin, L.; Alonso, M.; Girotti, A.; Javier Arias, F.; Carlos Rodriguez-Cabello, J.Synthesis and Characterization of Macroporous Thermosensitive Hydrogels from Recombinant Elastin-Like Polymers. Biomacromolecules, 2009, 10, 3015-3022.

[68] Ravi, S.; Haller, C. A.; Sallach, R. E.; Chaikof, E. L.Cell behavior on a CCN1 functionalized elastin-mimetic protein polymer. Biomaterials, 2012, 33, 2431-2438.

[69] Minato, A.; Ise, H.; Goto, M.; Akaike, T.Cardiac differentiation of embryonic stem cells by substrate immobilization of insulin-like growth factor binding protein 4 with elastin-like polypeptides. Biomaterials, 2012, 33, 515-523.

[70] Tirrell, M.; Kokkoli, E.; Biesalski, M.The role of surface science in bioengineered materials. Surf. Sci. 2002, 500, 61-83.

[71] Mitragotri, S.; Lahann, J.Physical approaches to biomaterial design. Nat. Mater. 2009, 8, 15-23.

[72] Raghavan, S.; Chen, C. S.Micropatterned Environments in Cell Biology. Adv. Mater. 2004, 16, 1303-1313.

[73] Bandiera, A.Human Elastin derived Biomimetic Coating Surface to Support Cell Growth. World Academy of Science, Engineering and Technology, 2010, 61, 30-34.

[74] Schulte, V. A.; Díez, M.; Mö ller, M.; Lensen, M. C.Surface Topography Induces Fibroblast Adhesion on Intrinsically
Nonadhesive Poly(ethylene glycol) Substrates. Biomacromolecules, 2009, 10, 2795-2801.

[75] Tejeda-Montes, E.; Smith, K. H.; Poch, M.; López-Bosque, M. J.; Martín, L.; Alonso, M.; Engel, E.; Mata, A.Engineering membrane scaffolds with both physical and biomolecular signaling. Acta Biomat. 2012, 8, 998-1009.

[76] Srokowski, E.; Woodhouse, K.Surface and adsorption characteristics of three elastin-like polypeptide coatings with varying sequence lengths. J. Mater. Sci: Mater. Med. 2013, 24, 7184.

[77] Srokowski, E. M.; Blit, P. H.; McClung, W. G.; Brash, J. L.; Santerre, J. P.; Woodhouse, K. A.Platelet Adhesion and Fibrinogen Accretion on a Family of Elastin-Like Polypeptides. J Biomater Sci, Polym Ed. 2011, 22, 41-57.

[78] Janorkar, A. V.; Rajagopalan, P.; Yarmush, M. L.; Megeed, Z.The use of elastin-like polypeptide-polyelectrolyte complexes to control hepatocyte morphology and function in vitro. Biomaterials, 2008, 29, 625-632.

[79] Barbosa, J. S.; Ribeiro, A.; Testera, A. M.; Alonso, M.; Arias, F. J.; Rodríguez-Cabello, J. C.; Mano, J. F.Development of Biomimetic Chitosan-Based Hydrogels Using an Elastin-Like Polymer. Adv. Eng. Mater, 2010, 12, B37-B44.

[80] Costa, R. R.; Custódio, C. A.; Testera, A. M.; Arias, F. J. Rodríguez-Cabello, J. C.; Alves, N. M.; Mano, J. F.StimuliResponsive Thin Coatings Using Elastin-Like Polymers for Biomedical Applications. Adv. Eng. Mater, 2009, 19, 3210-3218.

[81] González, M.; Salvagni, E.; Rodríguez-Cabello, J. C.; Rupérez, E.; Gil, F. J.; Peña, J.; Manero, J. M.A low elastic modulus Ti-Nb-Hf alloy bioactivated with an elastin-like protein-based polymer enhances osteoblast cell adhesion and spreading. J Biomed Mater Res $A$, 2012, 101, 819-826.

[82] Decher, G.Fuzzy Nanoassemblies: Toward Layered Polymeric Multicomposites. Science, 1997, 277, 1232-1237.

[83] Costa, R. R.; Custodio, C. A.; Arias, F. J.; Rodriguez-Cabello, J. C.; Mano, J. F.Layer-by-Layer Assembly of Chitosan and Recombinant Biopolymers into Biomimetic Coatings with Multiple Stimuli-Responsive Properties. Small, 2011, 7, 2640-2649.

[84] Golonka, M.; Bulwan, M.; Nowakowska, M.; Testera, A. M.; Rodriguez-Cabello, J. C.; Zapotoczny, S.Thermoresponsive multilayer films based on ionic elastin-like recombinamers. Soft Matter, 2011, 7, 9402-9409.

[85] Swierczewska, M.; Hajicharalambous, C. S.; Janorkar, A. V.; Megeed, Z.; Yarmush, M. L.; Rajagopalan, P.Cellular response to nanoscale elastin-like polypeptide polyelectrolyte multilayers. Acta Biomater. 2008, 4, 827-837.

[86] Costa, R. R.; Custódio, C. A.; Arias, F. J.; Rodríguez-Cabello, J. C.; Mano, J. F.Nanostructured and thermoresponsive recombinant biopolymer-based microcapsules for the delivery of active molecules. Nanomed.-Nanotechnol. Biol. Med. 2013, 9, 895-902.

[87] Kumar, A.; Srivastava, A.; Galaev, I. Y.; Mattiasson, B.Smart polymers: Physical forms and bioengineering applications. Prog. Polym. Sci. 2007, 32, 1205-1237.

[88] Kikuchi, A.; Okano, T.Intelligent thermoresponsive polymeric stationary phases for aqueous chromatography of biological compounds. Prog. Polym. Sci. 2002, 27, 1165-1193.

[89] Nath, N.; Chilkoti, A.Creating "Smart" Surfaces Using Stimuli Responsive Polymers. Adv. Mater. 2002, 14, 1243-1247.

[90] Nath, N.; Hyun, J.; Ma, H.; Chilkoti, A.Surface engineering strategies for control of protein and cell interactions. Surf. Sci. 2004, 570, 98-110.

[91] Fu, Q.; Rao, G. V. R.; Ista, L. K.; Wu, Y.; Andrzejewski, B. P.; Sklar, L. A.; Ward, T. L.; López, G. P.Control of molecular transport through stimuli-responsive ordered mesoporous materials. Adv. Mater. 2003, 15, 1262-1266.

[92] Lee, J.; Jung, J.; Na, K.; Heo, P.; Hyun, J.Polypeptide-Mediated Switchable Microarray of Bacteria. ACS Appl Mater Interfaces, 2009, 1, 1359-1363.

[93] Nakagami, H.; Morishita, R.; Maeda, K.; Kikuchi, Y.; Ogihara, T.; Kaneda, Y.Adipose Tissue-Derived Stromal Cells as a Novel Option for Regenerative Cell Therapy. J. Atheroscler. Thromb. 2006, 13, 77-81.

[94] Okano, T.; Yamada, N.; Okuhara, M.; Sakai, H.; Sakurai, Y.Mechanism of cell detachment from temperature-modulated, hydrophilic-hydrophobic polymer surfaces. Biomaterials, 1995, 16, 297-303. 
[95] Hannachi, I. E.; Yamato, M.; Okano, T.Cell sheet technology and cell patterning for biofabrication. Biofabrication, 2009, 1, 022002.

[96] Mie, M.; Mizushima, Y.; Kobatake, E.Novel extracellular matrix for cell sheet recovery using genetically engineered elastin-like protein. J. Biomed. Mater. Res. B, 2008, 86B, 283-290.

[97] Pierna, M.; Santos, M.; Arias, F. J.; Alonso, M.; RodríguezCabello, J. C.Efficient Cell and Cell-Sheet Harvesting Based on Smart Surfaces Coated with a Multifunctional and Self-Organizing Elastin-Like Recombinamer. Biomacromolecules, 2013, 14, 18931903.

[98] Uhrich, K. E.; Cannizzaro, S. M.; Langer, R. S.; Shakesheff, K. M.Polymeric systems for controlled drug release. Chem. Rev. 1999, 99, 3181-3198.

[99] Altunbas, A.; Pochan, D. J.Peptide-Based and Polypeptide-Based Hydrogels for Drug Delivery and Tissue Engineering. Top. Curr. Chem. 2012, 310, 135-167.

[100] Lee, M. K.; Kim, S.; Ahn, C. H.; Lee, J.Hydrophilic and hydrophobic amino acid copolymers for nano-comminution of poorly soluble drugs. Int. J. Pharm. 2010, 384, 173-180.

[101] Urry, D. W.; Gowda, D. C.; Harris, C. M.; Harris, R. D., Bioelastic materials and the $\Delta$ Tt-Mechanism in drug delivery. In Polymeric Drugs and Drug Administration, Ottenbrite, R. M., Ed. ACS: Washintong DC, 1994; p 15.

[102] Rodriguez-Cabello, J. C.; Gonzalez de Torre, I.; Pinedo, G., CHAPTER 19 Elastin-like Hydrogels and Self-assembled Nanostructures for Drug Delivery. In Smart Materials for Drug Delivery: Volume 2, The Royal Society of Chemistry: 2013; 2, pp 180-198

[103] Li, Y.; Rodrigues, J.; Tomas, H.Injectable and biodegradable hydrogels: gelation, biodegradation and biomedical applications. Chem. Soc. Rev. 2012, 41, 2193-2221.

[104] Hart, D. S.; Gehrke, S. H.Thermally associating polypeptides designed for drug delivery produced by genetically engineered cells. J. Pharm. Sci. 2007, 96, 484-516.

[105] Asai, D.; Xu, D.; Liu, W.; Garcia Quiroz, F.; Callahan, D. J.; Zalutsky, M. R.; Craig, S. L.; Chilkoti, A.Protein polymer hydrogels by in situ, rapid and reversible self-gelation. Biomaterials, 2012, 33, 5451-5458.

[106] McHale, M. K.; Setton, L. A.; Chilkoti, A.Synthesis and in vitro evaluation of enzymatically cross-linked elastin-like polypeptide gels for cartilaginous tissue repair. Tissue Eng. 2005, 11, 17681779.

[107] Lim, D. W.; Nettles, D. L.; Setton, L. A.; Chilkoti, A.Rapid crosslinking of elastin-like polypeptides with (hydroxymethyl)phosphines in aqueous solution. Biomacromolecules, 2007, 8, 1463-1470.

[108] Nagapudi, K.; Brinkman, W. T.; Leisen, J. E.; Huang, L.; McMillan, R. A.; Apkarian, R. P.; Conticello, V. P.; Chaikof, E. L.Photomediated Solid-State Cross-Linking of an Elastin-Mimetic Recombinant Protein Polymer. Macromolecules, 2002, 35, 17301737.

[109] Betre, H.; Liu, W.; Zalutsky, M. R.; Chilkoti, A.; Kraus, V. B.; Setton, L. A.A thermally responsive biopolymer for intra-articular drug delivery. J. Controlled Release, 2006, 115, 175-182.

[110] Liu, W.; MacKay, J. A.; Dreher, M. R.; Chen, M.; McDaniel, J. R.; Simnick, A. J.; Callahan, D. J.; Zalutsky, M. R.; Chilkoti, A.Injectable intratumoral depot of thermally responsive polypeptide-radionuclide conjugates delays tumor progression in a mouse model. J. Controlled Release, 2010, 144, 2-9.

[111] Betre, H.; Setton, L. A.; Meyer, D. E.; Chilkoti, A.Characterization of a genetically engineered elastin-like polypeptide for cartilaginous tissue repair. Biomacromolecules, 2002, 3, 910-916.

[112] Nagarsekar, A.; Crissman, J.; Crissman, M.; Ferrari, F.; Cappello, J.; Ghandehari, H.Genetic synthesis and characterization of $\mathrm{pH}-$ and temperature-sensitive silk-elastinlike protein block copolymers. J. Biomed. Mater. Res. 2002, 62, 195-203.

[113] Takahashi, Y.; Gehoh, M.; Yuzuriha, K.Structure refinement and diffuse streak scattering of silk (Bombyx mori). Int. J. Biol. Macromol. 1999, 24, 127-138.

[114] Cappello, J.; Crissman, J. W.; Crissman, M.; Ferrari, F. A.; Textor, G.; Wallis, O.; Whitledge, J. R.; Zhou, X.; Burman, D.; Aukerman, L.; Stedronsky, E. R.In-situ self-assembling protein polymer gel systems for administration, delivery, and release of drugs. $J$. Controlled Release, 1998, 53, 105-117.
[115] Megeed, Z.; Cappello, J.; Ghandehari, H.Genetically engineered silk-elastinlike protein polymers for controlled drug delivery. $A d v$. Drug Deliv. Rev. 2002, 54, 1075-1091.

[116] Gustafson, J. A.; Price, R. A.; Greish, K.; Cappello, J.; Ghandehari, H.Silk-elastin-like hydrogel improves the safety of adenovirusmediated gene-directed enzyme-prodrug therapy. Mol. Pharm. 2010, 7, 1050-1056.

[117] Greish, K.; Frandsen, J.; Scharff, S.; Gustafson, J.; Cappello, J.; Li, D.; O'Malley, B. W., Jr.; Ghandehari, H.Silk-elastinlike protein polymers improve the efficacy of adenovirus thymidine kinase enzyme prodrug therapy of head and neck tumors. J. Gene Med. 2010, 12, 572-579.

[118] Herrero-Vanrell, R.; Rincon, A. C.; Alonso, M.; Reboto, V.; Molina-Martinez, I. T.; Rodriguez-Cabello, J. C.Self-assembled particles of an elastin-like polymer as vehicles for controlled drug release. J. Controlled Release, 2005, 102, 113-122.

[119] Rincon, A. C.; Molina-Martinez, I. T.; de Las Heras, B.; Alonso, M.; Bailez, C.; Rodriguez-Cabello, J. C.; Herrero-Vanrell, R.Biocompatibility of elastin-like polymer poly(VPAVG) microparticles: in vitro and in vivo studies. J. Biomed. Mater. Res. A, 2006, 78, 343-351.

[120] Bessa, P. C.; Machado, R.; Nurnberger, S.; Dopler, D.; Banerjee, A.; Cunha, A. M.; Rodriguez-Cabello, J. C.; Redl, H.; van Griensven, M.; Reis, R. L.; Casal, M.Thermoresponsive selfassembled elastin-based nanoparticles for delivery of BMPs. $J$. Controlled Release, 2010, 142, 312-318.

[121] MacKay, J. A.; Chen, M.; McDaniel, J. R.; Liu, W.; Simnick, A. J.; Chilkoti, A.Self-assembling chimeric polypeptide-doxorubicin conjugate nanoparticles that abolish tumours after a single injection. Nat. Mater. 2009, 8, 993-999.

[122] Sallach, R. E.; Wei, M.; Biswas, N.; Conticello, V. P.; Lecommandoux, S.; Dluhy, R. A.; Chaikof, E. L.Micelle density regulated by a reversible switch of protein secondary structure. $J$. Am. Chem. Soc. 2006, 128, 12014-12019.

[123] Dreher, M. R.; Simnick, A. J.; Fischer, K.; Smith, R. J.; Patel, A.; Schmidt, M.; Chilkoti, A.Temperature triggered self-assembly of polypeptides into multivalent spherical micelles. J. Am. Chem. Soc. 2008, 130, 687-694.

[124] García-Arévalo, C.; Bermejo-Martín, J. F.; Rico, L.; Iglesias, V.; Martín, L.; Rodríguez-Cabello, J. C.; Arias, F. J.Immunomodulatory Nanoparticles from Elastin-Like Recombinamers: Single-Molecules for Tuberculosis Vaccine Development. Mol. Pharm. 2013, 10, 586-597.

[125] Kaldis, A,; Ahmad, A.; Reid, A.; McGarvey, B.; Brandle, J.; Ma, S.; Jevnikar. A.; Kohalmi, S.E.; Menassa. R. High-level production of human interleukin-10 fusions in tobacco cell suspension cultures. Plant Biotechnol. J. 2013, 11, 535-545.

[126] Shamji, M. F.; Whitlatch, L.; Friedman, A. H.; Richardson, W. J.; Chilkoti, A.; Setton, L. A.An injectable and in situ-gelling biopolymer for sustained drug release following perineural administration. Spine (Phila Pa 1976), 2008, 33, 748-754.

[127] Conrad, U.; Plagmann, I.; Malchow, S.; Sack, M.; Floss, D. M.; Kruglov, A. A.; Nedospasov, S. A.; Rose-John, S.; Scheller, J.ELPylated anti-human TNF therapeutic single-domain antibodies for prevention of lethal septic shock. Plant Biotechnol. J. 2011, 9, 22-31.

[128] Greish, K. Enhanced permeability and retention of macromolecular drugs in solid tumors: a royal gate for targeted anticancer nanomedicines. J. Drug Target. 2007, 15, 457-464.

[129] Dreher, M. R.; Liu, W.; Michelich, C. R.; Dewhirst, M. W.; Chilkoti, A.Thermal cycling enhances the accumulation of a temperature-sensitive biopolymer in solid tumors. Cancer Res. 2007, 67, 4418-4424.

[130] McDaniel, J. R.; Macewan, S. R.; Dewhirst, M.; Chilkoti, A.Doxorubicin-conjugated chimeric polypeptide nanoparticles that respond to mild hyperthermia. $J$ Controlled Release, 2012, 159, 362-367.

[131] Bidwell, G. L., 3rd; Raucher, D.Cell penetrating elastin-like polypeptides for therapeutic peptide delivery. Adv. Drug Deliv. Rev. 2010, 62, 1486-1496.

[132] Bidwell, G. L., 3rd; Davis, A. N.; Fokt, I.; Priebe, W.; Raucher D.A thermally targeted elastin-like polypeptide-doxorubicin conjugate overcomes drug resistance. Invest. New Drugs, 2007, 25, 313-326. 
[133] Bidwell, G. L., 3rd; Fokt, I.; Priebe, W.; Raucher, D.Development of elastin-like polypeptide for thermally targeted delivery of doxorubicin. Biochem. Pharmacol. 2007, 73, 620-631.

[134] Massodi, I.; Thomas, E.; Raucher, D.Application of Thermally Responsive Elastin-like Polypeptide Fused to a Lactoferrin-derived Peptide for Treatment of Pancreatic Cancer. Molecules, 2009, 14, 1999-2015.

[135] Macewan, S. R.; Chilkoti, A.Digital switching of local arginine density in a genetically encoded self-assembled polypeptide nanoparticle controls cellular uptake. Nano Lett. 2012, 12, 33223328.

[136] Rodriguez-Cabello, J. C.; Martin, L.; Girotti, A.; Garcia-Arevalo, C.; Arias, F. J.; Alonso, M.Emerging applications of multifunctional elastin-like recombinamers. Nanomedicine (London, U. K.), 2011, 6, 111-122.

[137] Kreibig, U.; Volmer, M., Optical properties of metal clusters. Springer: 1995.

[138] Shipway, A. N.; Katz, E.; Willner, I.Nanoparticle Arrays on Surfaces for Electronic, Optical, and Sensor Applications. Chemphyschem, 2000, 1, 18-52.

[139] Baraton, M.-I., Synthesis, functionalization and surface treatment of nanoparticles. American Scientific Publishers: Stevenson Ranch, Calif., 2003.

[140] Norman, T. J.; Grant, C. D.; Magana, D.; Zhang, J. Z.; Liu, J.; Cao, D.; Bridges, F.; Van Buuren, A.Near Infrared Optical Absorption of Gold Nanoparticle Aggregates. J. Phys. Chem. B, 2002, 106, 7005-7012.

[141] Brown, S. D.; Nativo, P.; Smith, J.-A.; Stirling, D.; Edwards, P. R.; Venugopal, B.; Flint, D. J.; Plumb, J. A.; Graham, D.; Wheate, N. J.Gold Nanoparticles for the Improved Anticancer Drug Delivery of the Active Component of Oxaliplatin. J. Am. Chem. Soc., 2010, $132,4678-4684$

[142] Stuchinskaya, T.; Moreno, M.; Cook, M. J.; Edwards, D. R.; Russell, D. A.Targeted photodynamic therapy of breast cancer cells using antibody-phthalocyanine-gold nanoparticle conjugates. Photochem. Photobiol. Sci., 2011, 10, 822-831.

[143] Alvarez-Rodriguez, R.; Alonso, M.; Girotti, A.; Reboto, V.; Rodriguez-Cabello, J. C.One-pot synthesis of $\mathrm{pH}$ and temperature sensitive gold clusters mediated by a recombinant elastin-like polymer. Eur. Polym. J., 2010, 46, 643-650.

[144] Lemieux, V.; Adams, P. H.; van Hest, J. C.Elastin-based stimuliresponsive gold nanoparticles. Chem. Commun. 2010, 46, 30713073.

[145] Nath, N.; Chilkoti, A.Interfacial phase transition of an environmentally responsive elastin biopolymer adsorbed on functionalized gold nanoparticles studied by colloidal surface plasmon resonance. J. Am. Chem. Soc. 2001, 123, 8197-8202.

[146] Anh, T. T.; Xing, M.; Le, D. H.; Sugawara-Narutaki, A.; Fong, E.Elastin-based silver-binding proteins with antibacterial capabilities. Nanomedicine (London, U. K.) 2013, 8, 567-575.
[147] Klostranec, J. M.; Chan, W. C. W.Quantum Dots in Biological and Biomedical Research: Recent Progress and Present Challenges. Adv. Mater. 2006, 18, 1953-1964.

[148] Lao, U. L.; Mulchandani, A.; Chen, W.Simple Conjugation and Purification of Quantum Dot-Antibody Complexes Using a Thermally Responsive Elastin-Protein L Scaffold As Immunofluorescent Agents. J. Am. Chem. Soc. 2006, 128, 1475614757.

[149] Fahmi, A.; Pietsch, T.; Bryszewska, M.; Rodríguez-Cabello, J. C.; Koceva-Chyla, A.; Arias, F. J.; Rodrigo, M. A.; Gindy, N.Fabrication of CdSe-Nanofibers with Potential for Biomedical Applications. Adv. Funct. Mater. 2010, 20, 1011-1018.

[150] Yang, K.; Zhang, S.; Zhang, G.; Sun, X.; Lee, S.-T.; Liu, Z.Graphene in Mice: Ultrahigh In vivo Tumor Uptake and Efficient Photothermal Therapy. Nano Lett. 2010, 10, 3318-3323.

[151] Sun, X.; Liu, Z.; Welsher, K.; Robinson, J.; Goodwin, A.; Zaric, S .; Dai, H.Nano-graphene oxide for cellular imaging and drug delivery. Nano Res. 2008, 1, 203-212.

[152] Hong, H.; Yang, K.; Zhang, Y.; Engle, J. W.; Feng, L.; Yang, Y.; Nayak, T. R.; Goel, S.; Bean, J.; Theuer, C. P.; Barnhart, T. E.; Liu, Z.; Cai, W.In vivo Targeting and Imaging of Tumor Vasculature with Radiolabeled, Antibody-Conjugated Nanographene. ACS Nano, 2012, 6, 2361-2370.

[153] Chen, G. Y.; Pang, D. W. P.; Hwang, S. M.; Tuan, H. Y.; Hu, Y C.A graphene-based platform for induced pluripotent stem cells culture and differentiation. Biomaterials, 2012, 33, 418-427.

[154] Wang, E.; Desai, M. S.; Lee, S.-W.Light-Controlled GrapheneElastin Composite Hydrogel Actuators. Nano Lett. 2013, 13, 28262830.

[155] Ribeiro, A.; Arias, F. J.; Reguera, J.; Alonso, M.; RodriguezCabello, J. C.Influence of the amino-acid sequence on the inverse temperature transition of elastin-like polymers. Biophys. J. 2009, 97, 312-320

[156] Martín, L.; Castro, E.; Ribeiro, A.; Alonso, M.; Rodríguez-Cabello, J. C.Temperature-Triggered Self-Assembly of Elastin-Like Block Co-Recombinamers:The Controlled Formation of Micelles an Vesicles in an Aqueous Medium. Biomacromolecules, 2012, 13, 293-298.

[157] Kim, W.; Thévenot, J.; Ibarboure, E.; Lecommandoux, S.; Chaikof E. L.Self-Assembly of Thermally Responsive Amphiphilic Diblock Copolypeptides into Spherical Micellar Nanoparticles. Angew. Chem., Int. Ed. Engl. 2010, 49, 4257-4260.

[158] Dash, B. C.; Mahor, S.; Carroll, O.; Mathew, A.; Wang, W. Woodhouse, K. A.; Pandit, A.Tunable elastin-like polypeptide hollow sphere as a high payload and controlled delivery gene depot. J. Controlled Release, 2011, 152, 382-392.

[159] Wu, Y.; MacKay, J. A.; McDaniel, J. R.; Chilkoti, A.; Clark, R. L.Fabrication of elastin-like polypeptide nanoparticles for drug delivery by electrospraying. Biomacromolecules, 2009, 10, 19-24. 